\title{
Um estudo comparativo da dinâmica microclimática em espaços adaptados para fins de conservação de acervos sob a ótica da sustentabilidade
}

A comparative study of the microclimatic dynamics in areas adapted for collection conservation purposes from the perspective of sustainability

https://doi.org/10.1590/1982-02672021v29e8

\author{
ANNA LAURA CANUTO ROCHA DE ANDRADE' \\ https: / / orcid.org/0000-0002-4382-6625 \\ Universidade de São Paulo / São Paulo, SP, Brasil
}

\author{
ANDREA CAVICCHIOLI \\ https://orcid.org/0000-0002-0303-2994 \\ Universidade de São Paulo / São Paulo, SP, Brasil
}

RESUMO: Este artigo resgata e apresenta os principais caminhos de aproximação entre o universo da conservação de bens culturais e as tendências da sustentabilidade, discutindo particularmente o papel do diagnóstico microclimático de espaços adaptados à função museológica na definição das estratégias de conservação preventiva embasadas nos princípios de tal movimento (identificadas por alguns autores como slow conservation). Esta análise se articula com dois estudos de caso que avaliam os comportamentos dinâmicos de parâmetros físico-ambientais (temperatura e umidade) coletados durante o período de um ano em espaços internos do Museu Paulista da Universidade de São Paulo (USP) e do Museu Casa da Xilogravura, confrontados com as variações climáticas externas. Os resultados e suas interpretações permitem ressaltar a importância do diagnóstico dos espaços

\begin{abstract}
1. Graduada em história pela Universidade Federal de Alagoas (UFAL). Mestra em sustentabilidade na Escola de Artes, Ciências e Humanidades (EACH) da Universidade de São Paulo (USP). Tem experiência na área de conservação de acervos, com ênfase em conservação preventiva. E-mail: <annalaura@usp.br>.

2. Graduado em química industrial pela Università degli Studi di Milano, mestre em química analítica ambiental pela University of London e doutor em química (química analítica) pela Universidade de São Paulo (USP). É professor associado da USP, atuando no curso de gestão ambiental, no mestrado e no doutorado do programa de pós-graduação interdisciplinar em sustentabilidade da EACH. E-mail: <andrecav@usp.br>.
\end{abstract}


de conservação, enquanto ferramenta de planejamento de ações preventivas alternativas às tradicionais abordagens de controle ambiental mecanizado e automatizado, e vislumbrar estratégias passivas que valorizem potencialidades existentes, minimizem vulnerabilidades isoladas e contribuam concretamente para a articulação com um mundo sustentável.

PALAVRAS-CHAVE: Sustentabilidade. Museus. Conservação Preventiva. Microclima.

ABSTRACT: The article retrieves and presents the main ways of combining the universe of cultural heritage conservation with the trends of sustainability and, especially, discusses the role of microclimate diagnostics of areas adapted to the museum function in the definition of preventive conservation strategies based on the principles of such movement lby some authors identified as slow conservation). This analysis is articulated with two case studies in which the dynamic behavior of physical-environmental parameters (temperature and humidity) collected during a oneyear interval in internal areas of two museums (Museu Paulista and Museu Casa da Xilogravura) are assessed, considering external climatic variations. The results and their interpretation allow corroborating the importance of diagnostics of conservation areas as a planning tool for preventive actions alternative to traditional approaches based on mechanized and automated environmental control. Moreover, they enable envisioning passive strategies that value existing potentials, minimize individual vulnerabilities and concretely contribute to the articulation with a sustainable world.

KEYWORDS: Sustainability. Museums. Preventive Conservation. Microclimate. 
Nos últimos anos, os profissionais engajados com a conservação dos bens culturais têm recebido cada vez mais apelos para aderir ao movimento da sustentabilidade e contribuir para incorporar seus princípios e práticas ao campo da preservação do patrimônio cultural: ${ }^{3}$

Em tempos de incertezas e de mudanças, é nossa responsabilidade prover as novas gerações de profissionais da conservação com o conhecimento e as habilidades necessários para enfrentar tais desafios e para desenvolver estratégias sustentáveis para a conservação do patrimônio cultural no século XXI. ${ }^{4}$

E ainda:

Agora, mais do que nunca, o campo dos bens culturais é confrontado com a necessidade de qualificar e quantificar suas contribuições fundamentais para a sociedade e a sustentabilidade. Seja por meio de benefícios ambientais, econômicos ou sociais, esse setor deve demonstrar de forma consistente como contribui para a melhoria da qualidade de vida das comunidades. Realinhar as metas de conservação do patrimônio cultural de maneira a garantir que sirvam ao bem maior da causa da sustentabilidade é um primeiro passo importante. ${ }^{5}$

A resposta a esses estímulos e demandas oscila entre duas grandes categorias de posicionamentos. Por um lado, desponta o anseio para o alinhamento filosófico entre sustentabilidade e conservação de bens culturais, resgatando a adesão a um objetivo comum de contestação à visão consumista e predatória do patrimônio natural e cultural, típica de modelos de desenvolvimento econômico da sociedade contemporânea. ${ }^{6}$

Essa postura partilha da ideia de que a efetiva concretização de um modelo de desenvolvimento sustentável se alicerça na promoção da sustentabilidade no campo cultural, num processo em que a cultura é enxergada como um "vetor para um crescimento social e econômico inclusivo"7 "que municia os povos e as comunidades com um forte sentimento de identidade e coesão social". ${ }^{8}$ Os mecanismos pelos quais a cultura colabora para a sustentabilidade são a promoção da educação e dos valores humanos, a proteção da diversidade cultural, o envolvimento das comunidades e a construção de capacidades locais. Dessa forma, "a sustentabilidade cultural está estritamente vinculada ao desenvolvimento sustentável por influenciar o comportamento das pessoas, as escolhas que fazem e
4. Cassar (2009, p. 10, tradução nossa). No original: "It is incumbent on all of us, in an age of uncertainty and change, to equip the next generation of heritage-conservation professionals with the knowledge and skills needed to enable them to face the challenges and to develop sustainable strategies for heritage conservation in the twentyfirst century".

5. Avrami (2011, p. 10, tradução nossa). No original: "Now, more than ever before, the heritage field is faced with the need to qualify and quantify its fundamental contributions to society and sustainability. Whether through environmental, economic, or social benefits, the field must robustly demonstrate how it improves quality of life for communities. Realigning the goals of heritage conservation to ensure that they serve the greater good of the sustainability cause is an important first step".

6. Cf. Cassar, op. cit.

7. Unesco (2016 apud FRONER, 2017, p. 215).

8. Unesco (2015 apud FRONER 2017, p. 216) 
9. Lähtinen e Myllyviita (2015 apud FRONER, 2017, p. 210, tradução nossa). No original: "Cultural sustainability is closely linked to sustainable development by affecting the way people behave and the choices they make as well as the overall welfare of society".

10. Unesco (2006 apud SILVA, 2011, p. 6).

11. Cf. Saunders (2008).

12. Cf. Mendes (2012).

13. Cf. Toledo (2010).

14. Cf. Ryhl-Svendsen et al. (2013).

15. Cf. Silva, op. cit.

16. Cf. De Silva e Henderson (2011).

17. Cf. Avrami, op. cit.

18. Cf. Boersma, Dardes e Druzik (2014); Cf. Paula (2008).

19. Cf. Cassar, op. cit., p. 6. o bem-estar geral da sociedade", ${ }^{9}$ e porque o reconhecimento e a valorização das diversidades "cria um mundo rico e variado que aumenta a gama de possibilidades e nutre as capacidades e valores humanos, constituindo, assim, um dos principais motores do desenvolvimento sustentável das comunidades, povos e nações". 10

Paralelamente, nota-se o desenvolvimento de um discurso ligado ao pilar ambiental da sustentabilidade, fortemente articulado às questões levantadas em nível global quanto às mudanças climáticas. Esse posicionamento vem estimulando a incorporação de valores como eficiência, flexibilidade e responsabilidade ambiental para potencializar e melhorar as práticas museológicas, que, especialmente nas duas últimas décadas, têm sido mais discutidas pelos profissionais visando compreender seus benefícios tanto para as instituições e coleções quanto para o meio ambiente e a sociedade. ${ }^{11}$ Iniciativas que incluem o uso de energias limpas, ${ }^{12} 0$ desenvolvimento de sistemas inteligentes para o controle ambiental ${ }^{13}$ e o estímulo à adoção de formas passivas com mínima intervenção mecânica para estabilização climática ${ }^{14}$ despontaram como alternativas reais, gerando importantes resultados positivos, apesar de não haver nenhuma exigência legal e a adoção desse posicionamento profissional ser unicamente resultado de uma escolha técnica, pessoal ou institucional.

Influenciados pelas tendências globais do final do século XX, os museus avançaram no campo social principalmente por meio de modelos sustentáveis de gestão institucional. ${ }^{15}$ No entanto, apenas nos últimos dez anos têm se debruçado mais ativamente sobre a importância de redefinir suas ações operacionais, especialmente nos critérios ambientais aplicados ao gerenciamento de seus ambientes. ${ }^{16}$ Nessa perspectiva, a área da conservação vem sendo desafiada a retomar o debate sobre a flexibilização dos padrões climáticos em ambientes de coleções diante da necessidade de reduzir o impacto ambiental de suas ações, assumindo um posicionamento mais empático e coordenado, visto que os profissionais precisam responder eficientemente às demandas impostas pelos efeitos das mudanças climáticas sobre o patrimônio cultural. ${ }^{17}$

Em razão da crescente adesão à sustentabilidade, ou por causa da pressão que ela exerce, as discussões mais recentes sobre controle ambiental em museus enfatizam a estabilidade microclimática mais do que a padronização de índices ambientais universais, a flexibilização dos padrões de qualidade e o reconhecimento das diversidades climáticas. ${ }^{18} \mathrm{~A}$ busca por soluções alternativas mais eficientes e econômicas que atendam à diversidade dos espaços, realidades climáticas e institucionais em prol da preservação dos bens culturais representa uma mudança de paradigma da conservação. Além disso, mesmo que ainda em fase embrionária em determinados contextos, já se trata de um processo que, na sua essência, harmoniza-se com o espírito da sustentabilidade. ${ }^{19}$ 
Essa tendência pode ser observada de forma generalizada em todo o mundo, como mostra o fato de o International Council of Museums - Committee for Conservation (Icom-CC) e o International Institute for Conservation (IIC) terem elaborado conjuntamente uma declaração com diretrizes ambientais que enfatiza a necessidade de uma associação estreita entre conservação, gestão e sustentabilidade, encorajando uma postura mais flexível nas determinações das condições ambientais de conservação dos acervos, buscando se harmonizar com as realidades locais e, sobretudo, comprometendo-se em minimizar os impactos ambientais, especialmente em vista das perspectivas de mudanças climáticas. ${ }^{20}$

$\bigcirc$ questionamento dos valores médios tradicionais de $50 \%( \pm 5 \%)$ de umidade relativa e $21{ }^{\circ} \mathrm{C}$ de temperatura tem ganhado expressividade no horizonte da sustentabilidade, em vista do alto consumo energético necessário para sustentar esse padrão e dos riscos aos materiais em função da total dependência de recursos mecanizados (de custo elevado e difícil manutenção) que, frequentemente, são incompatíveis com o alcance financeiro e técnico de muitas instituições. ${ }^{21}$ Considerando a variedade climática no planeta, a dificuldade de alcançar esses valores torna-se mais um obstáculo devido aos problemas de estabilização que ocorrem mesmo em regiões com climas semelhantes, ${ }^{22}$ gerando também impasses políticos, principalmente ao se estabelecerem padrões ambientais para empréstimos entre instituições. ${ }^{23}$

Considerando essa diversidade de fatores e as peculiaridades de cada tipo climático, a simples reprodução de padrões ambientais universais se torna um fator complicador quando se adota a estabilidade como qualidade imprescindível aos espaços de conservação, visto que, dentro de uma mesma tipologia climática, elementos como topografia, altitude e interferências antropogênicas (por exemplo, a presença ou ausência de vegetação em zonas urbanas) repercutem nos ambientes internos. ${ }^{24}$ Em áreas de clima tropical, a adoção de parâmetros tradicionais de temperatura e umidade relativa universais desconsidera a positiva estabilidade climática sazonal (em comparação aos climas temperados), pois submete as coleções a sistemas mecanizados sujeitos a panes e em desacordo com a realidade climática local, aumentando os riscos de grandes e constantes instabilidades ambientais. ${ }^{25}$ Apesar das temperaturas mais elevadas, as estratégias baseadas principalmente em padrões térmicos mais conservadores - utilizando apenas arcondicionado, por exemplo - não têm se demonstrado um modelo sustentável, tanto por sua influência negativa nos índices de umidade relativa como pelo gasto energético e financeiro com a manutenção dos sistemas mecânicos artificiais. ${ }^{26}$

$\bigcirc$ conhecimento aprofundado dos efeitos dos fatores ambientais sobre os materiais e das diferentes escalas microclimáticas que os cercam tem levado pesquisadores e profissionais da conservação a se debruçarem mais ativamente sobre
20. Cf. $<$ http://bit. 1y/3jOZWSp $>$. Acesso em: 12 jul. 2020.

21. Cf. King e Pearson (2001).

22. Cf. Toledo, op. cit.

23. Cf. Ashley-Smith, Umney e Ford (1994).

24. Cf. Teijgeler (2007).

25. Cf. Toledo (2006).

26. Cf. Ashley-Smith, Umney e Ford, op. cit.; Cf. Toledo (2010). 
27. Cf. Cavicchioli (2017).

28. Cf. Gonçalves e Souza (2014).

29. Cf. Neves (2006).

30. Cf. Gonçalves, Souza e Froner (2008).

31. Cf. Toledo (2006). ações de caracterização dos espaços para identificar potencialidades e limitações em seus ambientes, de forma a embasar suas decisões e direcionar recursos, aumentando a eficiência de suas ações e criando uma importante ferramenta de conservação, tornando-se uma premissa fundamental para definir o tipo de estratégia de controle ambiental a ser adotada, bem como a principal ferramenta de conservação preventiva. ${ }^{27}$

O uso de sistemas alternativos de controle climático dos espaços de conservação é desencorajado pela crença na adoção de parâmetros muito restritivos, que recorrem frequentemente a ações totalmente mecanizadas que podem não ser adequadas às construções ou ao próprio clima. Flexibilizar os parâmetros e buscar espaços que garantam maior estabilidade às coleções é um estímulo para que se adotem formas passivas de controle ambiental. Nessa perspectiva, a arquitetura bioclimática tem feito importantes considerações sobre o papel das edificações nas dinâmicas climáticas internas: bloqueando, favorecendo ou modulando trocas de calor e umidade com o ambiente externo. ${ }^{28}$ Esse conceito de arquitetura se difundiu a partir da década de 1960, englobando valores relacionados à economia energética, ao conforto e à redução de danos ambientais por meio da harmonização entre as construções e o local onde estão inseridas, principalmente com o uso de sistemas passivos para controle ambiental das áreas internas e com o emprego de técnicas e materiais de construção específicos e eficientes para adequar as construções ao ambiente. ${ }^{29}$

A adaptação de espaços para a função de museu é uma prática comum e pode representar uma alternativa interessante em vista da redução dos impactos ambientais que seriam gerados por novas construções. $\bigcirc$ funcionamento de museus em prédios antigos é bastante usual, inclusive como forma de valorizar algumas edificações, por motivos artísticos, arquitetônicos ou históricos. Nessa adaptação de construções a uma nova função, ressalta-se a necessidade de um diagnóstico microclimático dos ambientes internos que envolva também uma avaliação da edificação, de seu entorno e das rotinas institucionais a fim de se compreender as dinâmicas climáticas atuantes nos espaços e conhecer suas potencialidades e fragilidades, permitindo melhor aproveitamento do local e direcionando recursos de forma a garantir boas condições de ocupação aos profissionais e visitantes, bem como de armazenagem e exposição das coleções, mantendo-as acessíveis e preservadas por mais tempo. ${ }^{30}$

Construções antigas podem apresentar importantes contribuições para a adoção de estratégias de controle ambiental mais sustentáveis, visto que foram projetadas para responder de forma mais autônoma às condições externas, com reconhecida capacidade de amortecimento das variações de temperatura e umidade, o que, principalmente em um clima tropical, é uma propriedade muito valorizada. ${ }^{31}$ 
Essas construções, a princípio, podem contribuir para gerar maior estabilidade nas condições internas, em razão de sua estrutura mais robusta e das paredes mais grossas, funcionando como amortecedor das oscilações ambientais externas e evitando os picos de temperatura e umidade, de maneira a responder aos estímulos externos sem depender de sistemas mecânicos ativos graças às propriedades arquitetônicas do design e das técnicas e materiais originalmente empregados na construção. ${ }^{32}$ Ao passo que a arquitetura moderna dissociou o controle climático de suas funções, em vista da disponibilidade de recursos e de materiais tecnológicos para essa finalidade, estabeleceram-se novas diretrizes construtivas baseadas principalmente na adoção do isolamento térmico, por se tratar de construções menos robustas do que as construções antigas, o que as tornou fortemente dependentes de sistemas mecânicos que nem sempre estão de acordo com as necessidades de conservação de acervos, principalmente quanto à umidade. ${ }^{33}$

Especialmente em locais sem sistema de controle ambiental mecanizado (antigo ou moderno), as condições microclimáticas internas são influenciadas pelo clima exterior, por trocas de temperatura e umidade mediadas direta ou indiretamente pelas características construtivas de cada edificação, além de sofrerem interferência das rotinas internas de cada instituição, resultando em um microclima interno próprio. ${ }^{34}$ Ainda assim, os padrões ambientais clássicos de conservação para adequação desses espaços continuam sendo perseguidos, desconsiderando as diretrizes técnicas de construção e, constantemente, utilizando o ar-condicionado como principal mecanismo de controle climático, ainda que em alguns casos esses espaços não tenham sido projetados para comportar esse tipo de interferência. ${ }^{35}$

Soluções alternativas baseadas no desenvolvimento de sistemas híbridos para controle ambiental em museus demonstraram importantes resultados na construção de estratégias mais econômicas e eficientes. Essas ações se basearam no conhecimento das dinâmicas microclimáticas internas de instituições e na recuperação das propriedades arquitetônicas ou materiais construtivas originais das edificações, contribuindo para a manutenção estrutural e preservação dos edifícios devido, em alguns casos, ao valor histórico, agregando visibilidade e importância social à edificação enquanto bem cultural. ${ }^{36}$

Estudos desenvolvidos em regiões de clima tropical apresentaram resultados inspiradores do ponto de vista da sustentabilidade, com o desenvolvimento de sistemas alternativos para controle ambiental, adaptados às necessidades dos materiais e à funcionalidade dos ambientes. Em ambos os casos o ponto de partida foi o controle da umidade relativa nos espaços e o estímulo ao uso da ventilação e circulação de ar nas áreas internas, permitindo maior flutuação de temperatura.
32. Cf. Ribeiro e Lomardo (2016).

33. Cf. Padfield e Larsen (2003).

34. Cf. MacLeod (2015).

35. Cf. Ribeiro e Lomardo, op. cit.

36. Cf. Toledo (2006). 
37. Maekawa e Toledo (2001).

38. Maekawa et al. (2009).

39. Cf. Gonçalves, Souza e Froner, op. cit.; Cf. Toledo (2010).
O estudo de Maekawa e Toledo ${ }^{37}$ foi realizado em uma instituição nas llhas Canárias, em prédio de alvenaria do final do século XIX que enfrentava problemas de biodeterioração. $\bigcirc$ sistema foi desenvolvido para reduzir e controlar os níveis de umidade relativa a partir do aquecimento e ventilação das salas mais frias do edifício, utilizando tecnologia simples, de baixo custo e de fácil manutenção, visando conservar melhor as coleções orgânicas. Essa estratégia pretendeu complementar as ações de recuperação das propriedades originais do edifício por meio da restauração da ventilação original de seu interior, de forma a atingir as necessidades de conservação do acervo, resultando em uma ação positiva que conseguiu manter abaixo dos $70 \%$ a umidade relativa durante todo o ano, além de reduzir o consumo de energia no prédio.

De forma semelhante, estudo de Maekawa et al. ${ }^{38}$ foi realizado em uma instituição no Rio de Janeiro, numa edificação de alvenaria do final do século XVIII, mais especificamente na sala da biblioteca, com foco na melhoria da circulação de ar original, da ventilação interna e na instalação de novos mecanismos visando diminuir o gasto energético e melhorar as condições ambientais internas, não apenas para a conservação do acervo, mas para o conforto dos visitantes. As ações focaram na recuperação das propriedades arquitetônicas do prédio e na construção de estratégias híbridas de controle ambiental (ativas e passivas) vislumbrando maior estabilidade do espaço (média de $25{ }^{\circ} \mathrm{C}$ de temperatura e $60 \%$ de umidade relativa). $\bigcirc$ sistema desenvolvido atuava automaticamente de acordo com as necessidades do museu durante sua rotina, ajustando a ventilação, resfriamento, desumidificação e circulação de ar a partir da leitura das condições internas da biblioteca em diferentes turnos. $\bigcirc$ projeto foi pioneiro ao apresentar rotas alternativas para o controle ambiental de locais quentes e úmidos, sugerindo novas abordagens para a conservação ao buscar o equilíbrio entre as necessidades do prédio, do acervo e dos visitantes.

Cabe observar que, segundo a perspectiva da sustentabilidade, diminui a expectativa de desenvolver padrões gerais aplicáveis indistintamente a todos os prédios antigos, históricos ou quaisquer outros espaços que assumiram a função de museu. Paralelamente, cresce a importância do monitoramento microclimático enquanto importante ferramenta de planejamento, que vai além da mera instalação de equipamentos de obtenção de dados para adoção de padrões previamente definidos de temperatura e umidade relativa, pois valoriza a identificação e compreensão de vulnerabilidades e potencialidades nesses espaços em função da estrutura física da edificação e da capacidade institucional de sustentar suas decisões. ${ }^{39}$

Assim, um diagnóstico ambiental objetivo e confiável dos locais que abrigam acervos culturais se torna ponto de partida para definir ações de gestão 
em espaços de conservação. Em vista disso, este trabalho buscou mostrar, por meio do estudo de dois casos específicos, uma possível abordagem para se compreender as dinâmicas microclimáticas higrotérmicas em ambientes indoor adaptados à função de museu, verificando suas potencialidades e fragilidades enquanto espaços destinados à conservação de coleções, e buscando harmonizar os princípios da conservação preventiva e da sustentabilidade para interpretar esses espaços como primeira camada de proteção de seus acervos.

\section{MATERIAIS E MÉTODOS}

\section{Desenho metodológico}

Para discutir as dinâmicas microclimáticas em espaços adaptados de construções históricas, conforme a perspectiva da conservação de acervos culturais num contexto climático tropical, foram planejadas duas campanhas de levantamento de dados primários de temperatura e umidade relativa no interior de casarões do estado de São Paulo, construídos na primeira metade do século XX e localizados na capital e na cidade de Campos do Jordão.

Por estarem inseridos num sistema regional de clima tropical de altitude, ainda que com diferenças bastante expressivas, principalmente em razão da altitude (aproximadamente $700 \mathrm{~m}$ na capital e 1600m em Campos do Jordão), os locais foram escolhidos com o intuito de analisar as dinâmicas microclimáticas em situações afetadas por uma alternância similar de estações (seca e úmida), mas com patamares térmicos distintos.

As campanhas foram realizadas num período de 365 dias, com registros automáticos de dados horários de temperatura do ar e umidade relativa feitos em um ponto interno de cada um dos casarões onde atualmente são conservadas as coleções. Em ambos os casos foram utilizados os dados oficiais de estações meteorológicas locais para observar as dinâmicas exteriores das duas variáveis.

\section{Descrição dos espaços monitorados}

Na cidade de São Paulo, o estudo foi realizado na Reserva Técnica do Serviço de Documentação Histórica e Iconografia (SVDHICO) do Museu Paulista 
40. Makino et al. (2003).

41. Cf. Ferroni et al. (2020).
(MP) da Universidade de São Paulo (USP). O MP é um museu universitário ligado à USP desde 1963 e estima-se que seu acervo contenha mais de 450 mil itens entre objetos, documentos textuais e iconográficos dos séculos XVII ao XX, compondo um dos principais acervos do país sobre a história da sociedade brasileira, em especial a paulista, com importante contribuição para os estudos de cultura material. ${ }^{40} \bigcirc$ edifício do museu é uma construção do final do século XIX e está situado dentro do Parque da Independência, fazendo parte de um complexo que engloba outras construções. O Parque da Independência foi concebido em 1910 e é um dos mais antigos conjuntos urbanísticos da cidade de São Paulo. ${ }^{41}$

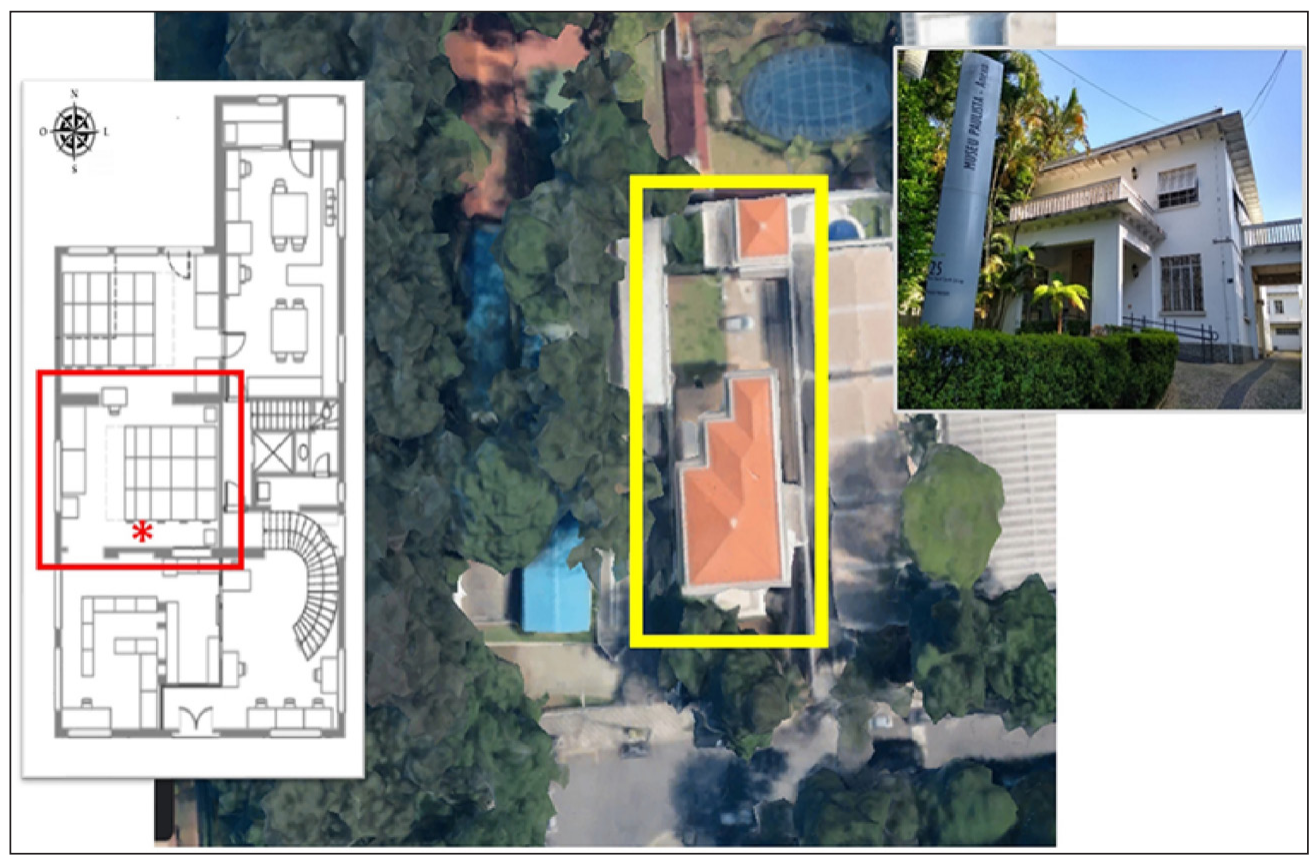

Figura 1 - Imóvel que sedia a Reserva Técnica do Museu Paulista. Na imagem central: localização da casa, situada entre a vegetação do Parque da Independência e outras construções, em imagem com zoom a 150m do solo. À esquerda: planta baixa do piso térreo com distribuição de móveis e destaque (em vermelho) para a área central da reserva técnica que foi monitorada; o ponto em destaque é a localização do aparelho de monitoramento. À direita: foto da fachada do imóvel. Fonte: Google Earth (<http://bit.ly/3poimdB>. Acesso em: 8 ago. 2020), Museu Paulista.

Em 2017, por causa da necessidade de esvaziar o edifício para as obras de restauro, iniciou-se o processo de transferência dos serviços técnicos, administrativos e de todo o acervo para espaços alternativos nas proximidades do Parque da Independência. O imóvel destinado ao SVDHICO está localizado a poucos metros da sede original do museu e é uma construção de 1949, com terreno de $981 \mathrm{~m}^{2}$ e $800 \mathrm{~m}^{2}$ de área construída, conforme destaque em amarelo na Figura 1. Originalmente 
o imóvel foi uma casa unifamiliar de classe média alta de dois pavimentos e uma edícula. No térreo da casa principal estão a varanda e o hall de entrada, além de salas, escritório, copa, cozinha, banheiro, acesso ao pavimento superior por escadas (social e de serviço), elevador (atualmente inativo), jardim no recuo frontal e um pomar nos fundos. $\bigcirc$ pavimento superior da casa principal tem suítes, closet e terraços.

As técnicas construtivas empregadas são compatíveis com as utilizadas em edificações de alto padrão da metade do século XX, apresentando paredes de alvenaria de tijolos, lajes de concreto armado, coberturas de telha cerâmica sobre estrutura de madeira, janelas e portas externas de ferro e vidro, e portas internas de madeira. Não conta com porão, porém apresenta discreta elevação de solo. As adaptações no imóvel para o uso atual compreenderam a compartimentação do espaço social no piso térreo para comportar a reserva técnica e área de pesquisa. Outras alterações foram realizadas no espaço da copa e no térreo da edícula para receber o laboratório de conservação e restauro. $\bigcirc$ espaço destinado à reserva técnica está situado no piso térreo, tem piso de mármore, é separado das áreas de consulta por parede de drywall e está dividido em três espaços interligados, orientados na face oeste e sem nenhum dispositivo de controle climático. ${ }^{42}$

A área monitorada, destacada em vermelho na Figura 1, conta com grandes janelas de vidro e esquadrias de metal permanentemente fechadas, sem uso de filtro para luz, cortinas ou persianas. Esse espaço abriga de mais de duzentas coleções (textual e iconográfica), incluindo toda a produção documental do museu no período de 1893 a 1963, além de itens de diferentes tipologias, sendo basicamente composto de papel e fotografias de formatos variados (incluindo filmes e objetos). No imóvel estão concentradas as atividades de conservação, documentação e fotografia do museu, além do atendimento aos pesquisadores e de estar aberto ao público (apenas com agendamento prévio).

Em Campos do Jordão o estudo foi realizado na sala de exposição do Museu Casa da Xilogravura (MX). O prédio data de 1928 e desde 1987 funciona como museu. Contém obras de xilogravura de mais de mil gravadores e mantém exposições de curta e longa duração, bem como matrizes em madeira, conforme destaque em amarelo na Figura 2. $\bigcirc$ museu está aberto ao público para visitas, realização de exposições, eventos culturais, cursos de xilogravura e tipografia, além de dispor de biblioteca especializada e ateliê xilográfico.

A construção conta com trinta salas de exposição, todas distribuídas praticamente no mesmo nível ou, no máximo, num pavimento rebaixado a partir da sala 7, conforme destaque em vermelho na Figura 2, onde foi realizado o monitoramento. Somente o bloco (original) mais ao norte apresenta um sótão estruturado para atividades administrativas. A sala monitorada destina-se à exposição 
permanente de obras expostas, que são impressões em papel em molduras de vidro. Nenhuma das salas do museu tem dispositivo para o controle climático ou da ventilação mecânica. Algumas têm janelas de vidro, de várias dimensões, que permanecem fechadas o tempo todo, sem uso de filtro, cortinas ou persianas. São orientadas a oeste, leste ou sul, e algumas estão próximas (alguns metros) de área de vegetação. O local funciona de quinta a segunda-feira, das nove às doze horas e das catorze às dezessete horas, fechando no período de 1 a 25 de dezembro.

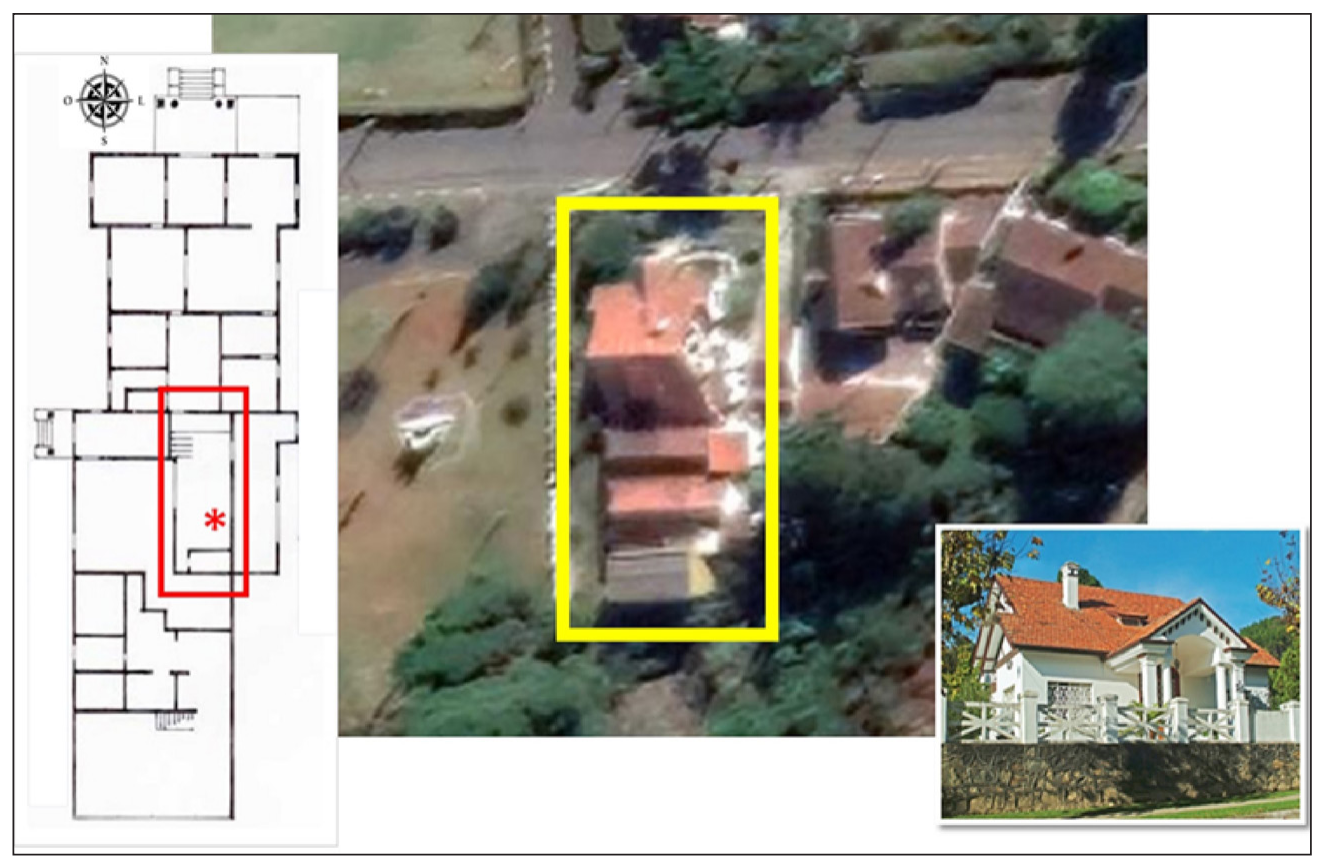

Figura 2 - Imóvel que sedia o Museu Casa da Xilogravura. Na imagem central: localização da casa, situada em área residencial com vegetação, em imagem com zoom a 150m do solo. À esquerda: planta baixa do museu com disposição das salas e destaque (em vermelho) para a área monitorada (sala 7). À direita: foto da fachada do imóvel. Fonte: Google Earth (<http:// bit.ly/3poimdB>. Acesso em: 8 ago. 2020) e site do Museu Casa da Xilogravura (<http://bit. ly/3b92bMp>. Acesso em: 8 ago. 20201

\section{Monitoramento}

Este trabalho focou no monitoramento de temperatura e umidade para uma análise da dinâmica microclimática da reserva técnica do MP e da sala de exposição do MX. Os intervalos temporais abrangeram o período de 21 de março de 2018 a 21 de março de 2019, no caso da Reserva Técnica do MP, e de 10 de julho de 2015 a 9 de julho de 2016 para a sala de exposição do MX. O fato de os períodos serem distintos não foi considerado prejudicial para o êxito das 
análises, uma vez que não se pretendia realizar uma comparação direta entre os dois espaços, a não ser, eventualmente, quanto às diferentes respostas às pressões climáticas oriundas do ambiente exterior. Por esse motivo, os resultados de cada monitoramento interior foram comparados com os dados meteorológicos externos coletados nos respectivos períodos. Entretanto, cabe relatar que os dados dos meses de março dos dois períodos de monitoramento foram excluídos da análise por causa de um grande número de lacunas num dos dois conjuntos de medidas, o que impossibilitaria uma avaliação confiável.

A análise mensal/sazonal buscou uma visualização melhor dos valores médios calculados a partir dos dados horários coletados, possibilitando uma leitura mais clara das potencialidades e limitações de cada espaço no contexto das rotinas de cada instituição. Para a caracterização ambiental foram comparados os ambientes externos e internos no mesmo período, a fim de verificar as dinâmicas dos espaços internos, considerando a influência do clima local no interior da edificação, base para elaboração do diagnóstico ambiental dos espaços para a conservação das coleções. ${ }^{43}$

Para realizar a caracterização ambiental externa, dados físicos ambientais de temperatura, umidade relativa e pressão atmosférica foram disponibilizados pelo Centro de Gerenciamento de Emergências Climáticas (CGE) e pelo Instituto Nacional de Meteorologia (Inmet), a partir das estações Ipiranga (localizadas na cidade de São Paulo, a $7 \mathrm{~km}$ do MP) e Campos do Jordão (localizada a $4 \mathrm{~km}$ do $M X)$, respectivamente. Quanto à precipitação, foram usados dados disponibilizados pelo Centro Nacional de Monitoramento e Alertas de Desastres Naturais (Cemaden), cuja estação localiza-se no bairro do Ipiranga, em São Paulo.

A região Sudeste do Brasil tem uma notável diversificação climática, com consideráveis variações de temperatura. Está localizada numa região de transição entre o clima tropical e o temperado, e apresenta temperaturas mais amenas, estações do ano mais delineadas do que as da faixa tropical (mais ao norte) e maior amplitude térmica anual. $\bigcirc$ clima na cidade de São Paulo é caracterizado por um verão moderadamente quente (sem temperaturas máximas muito elevadas) e por um inverno com temperaturas mais amenas devido à altitude. A cidade de Campos do Jordão situa-se na área de clima mesotérmico médio, marcado por temperaturas mais amenas durante todo o ano causadas pela influência da altitude, sendo considerado um dos climas mais frios do Brasil. ${ }^{44}$

Os data loggers utilizados no monitoramento interno são da marca Onset (USA), modelo U10-003, com margem de erro de 0,5 ${ }^{\circ} \mathrm{C}$ e 3,5\% para temperatura e umidade relativa, respectivamente, instalados na parede dos espaços selecionados, como indicado no ponto destacado nas Figuras 1 e 2, a uma altura de $2 \mathrm{~m}$. Foram escolhidos por sua grande capacidade de armazenamento de dados e praticidade
43. Os estudos de Gonçalves (2013) e Cavicchioli, Alegre e Martins (2017) funcionaram como norteadores para escolha e configuração de equipamentos utilizados, bem como para o tratamento e análise de dados de temperatura $(\mathrm{T})$ e umidade (UR), ainda que a sistematização dos dados em uma análise mensal tenha sido uma opção adotada para esta pesquisa para uma melhor visualização dos resultados anuais.

44. Cf. Nimer (1989). 
no cálculo automático das mínimas, médias e máximas, além da facilidade de manuseio e autonomia energética, necessária por causa do período de monitoramento.

\section{RESULTADOS E DISCUSSÕES}

\section{Resultados da Reserva Técnica do Museu Paulista}

Oexame do perfil térmico do espaço da Reserva Técnica do MP (Figura 3A) mostra que a variação sazonal da temperatura acompanha, de forma evidente, a dinâmica externa, confirmando que o clima regional é determinante no microclima interno, fato já esperado devido à ausência de controle ambiental nesses locais. Em todos os meses as temperaturas médias mensais nos espaços internos foram sempre mais elevadas do que as externas.

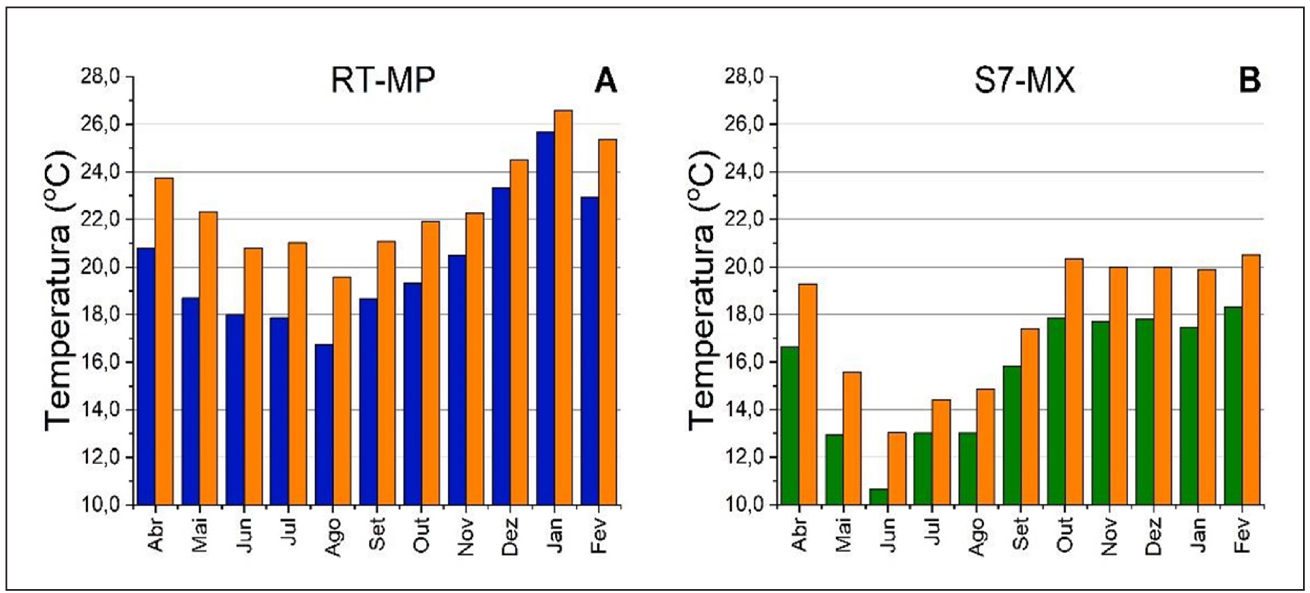

Figura 3 - Médias mensais de temperatura na reserva técnica do MP (A) e na sala 7 do MX (B). Na figura A. As barras azuis representam os valores externos e as laranjas os valores internos. Na figura $B$, as barras verdes indicam os valores externos e as laranjas os internos. Os dados dos meses de março foram desconsiderados devido a falhas no equipamento.

Durante os meses mais frios (de maio a novembro), as temperaturas médias mensais atingem no máximo $22,3^{\circ} \mathrm{C}$ (maio e novembro), quadro decorrente das características do clima da região e da queda da temperatura local, implicando uma temperatura média interna de $21,3{ }^{\circ} \mathrm{C}$ nesse período. A menor média mensal das mínimas diárias internas é de $19,2{ }^{\circ} \mathrm{C}$ (agostol e a maior média 
mensal das máximas internas é de $22,7^{\circ} \mathrm{C}$ (maio e novembro); a média das amplitudes diárias nesse período é de $0,8{ }^{\circ} \mathrm{C}$.

A diferença entre a temperatura média interna da Reserva Técnica do MP e o exterior do prédio nos meses invernais é de aproximadamente $2{ }^{\circ} \mathrm{C}$ (Figura 4A, barras cinzas) e é predominantemente influenciada pela diferença nas temperaturas mínimas (Figura 4A, barras azuis) que ocorrem nas primeiras horas da manhã, indicando que o ambiente interior tem uma marcante capacidade de conservar calor durante a noite. A proximidade maior entre as temperaturas internas e a faixa mais elevada das temperaturas externas é perceptível também no gráfico da Figura 5A.

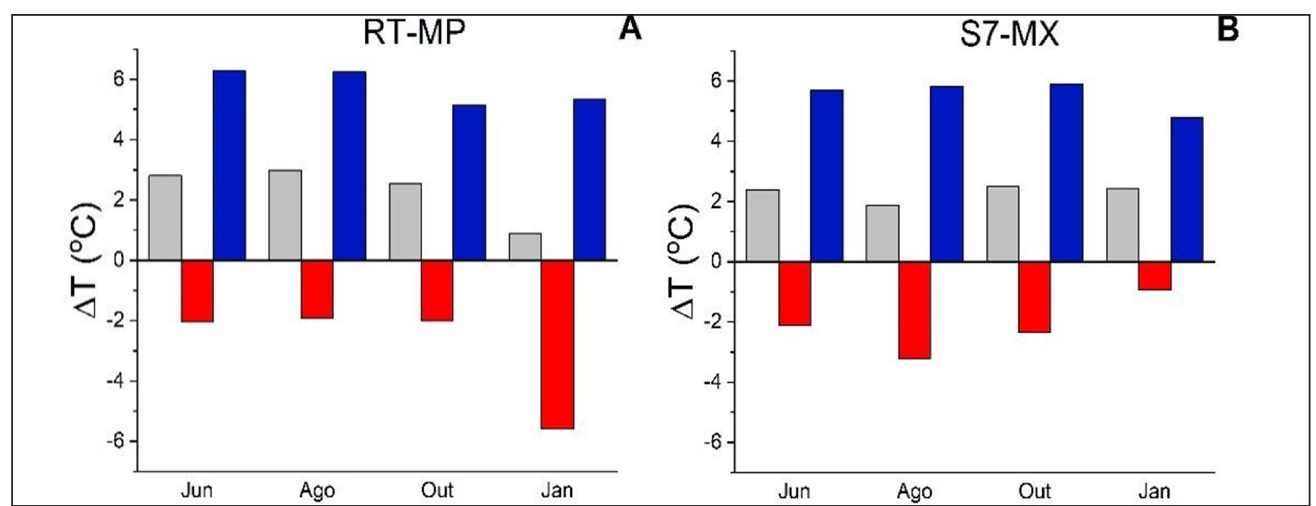

Figura 4 - Diferenças entre as médias mensais internas e externas de temperatura na Reserva Técnica do $M P(A)$ e na sala 7 do $M X(B)$. As barras cinzas mostram a diferença entre os valores médios, as azuis entre os valores mínimos e as vermelhas entre os valores máximos.

Ora, pode-se obter melhor entendimento da dinâmica de aquecimento/ resfriamento diário dos locais interiores da Reserva Técnica durante o período mais frio por meio da exemplificação dos ciclos diários mostrada na Figura 6A. Em todos os gráficos foram escolhidas sequências de três dias de tempo estável, no meio da estação e não coincidentes com dias de suspensão das atividades da instituição.

As curvas referentes ao MP durante o inverno, ainda que não se reproduzam de forma idêntica em todos os dias do período, mostram as seguintes características: (1) A fase de aquecimento começa (geralmente por volta das nove horas) com um atraso de aproximadamente duas horas em relação ao início do processo de aquecimento do ar exterior Igeralmente por volta das sete horas no inverno, considerando que em 20 de julho de 2018 o nascer do sol aconteceu, em São Paulo, às 6h48). $\bigcirc$ pico é alcançado às catorze horas, determinando uma taxa média de aquecimento de $0,28{ }^{\circ} \mathrm{C} / \mathrm{h}$ em relação a uma velocidade de $1,5^{\circ} \mathrm{C} / \mathrm{h}$ para o ar externo; (2) a taxa média de resfriamento do ar interno (processo que se estende por dezenove horas) é de $0,05^{\circ} \mathrm{C} / \mathrm{h}$, apresentando, no entanto, no fim de tarde (tipicamente a partir das dezessete horas) uma queda nítida. 

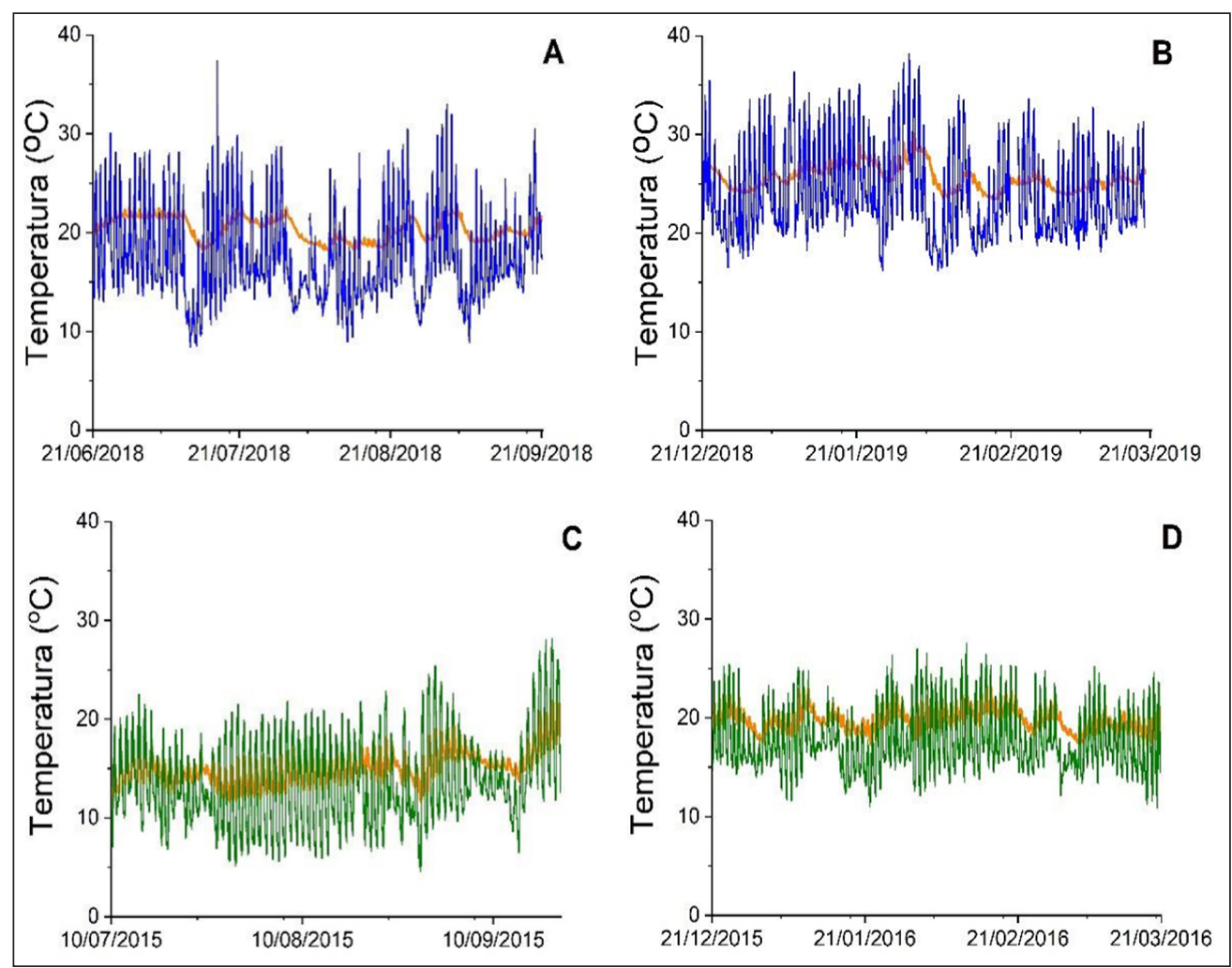

Figura 5 - Gráficos dos valores horários de temperatura da Reserva Técnica do MP no inverno (A) e no verão (B) e da sala 7 do $M X$ nas mesmas estações (C e D). Nas Figuras $A$ e $B$ as linhas azuis representam os valores externos e as linhas laranja os valores internos. Nas Figuras $C$ e D as linhas verdes indicam os valores externos e as linhas laranja os valores internos.

Fica evidente, então, que as dinâmicas de aquecimento/resfriamento do ar interno são muito amenizadas em relação ao ar externo nessa estação, inclusive por causa da influência da localização específica da sala e da orientação do casarão quanto à posição do Sol. De manhã, a edificação recebe irradiação pelo lado leste e, de tarde, pelo lado oeste, onde ficam as paredes externas da Reserva Técnica. Isso explica o atraso no início do ciclo de aquecimento do ar interno em relação ao ar externo, sugerindo que o ar da Reserva Técnica aqueça principalmente como consequência do aquecimento do ar exterior, à medida que passa gradativamente a circular internamente. A incidência dos raios de sol no lado oeste do casarão, por outro lado, colabora para o forte amortecimento na curva de resfriamento do ar no período vespertino. Também é muito provável que a rotina de uso do espaço exerça alguma influência nessa dinâmica, uma vez que o início do ciclo de aquecimento matutino coincide com o horário de abertura da reserva técnica, horário que, com frequência, atrasa de uma a duas horas nos fins de semana, quando não há atividades dentro da Reserva Técnica. A mudança na 
inclinação da curva de resfriamento por volta das dezessete horas pode igualmente ser interpretada à luz do papel da circulação de pessoas nesse espaço.

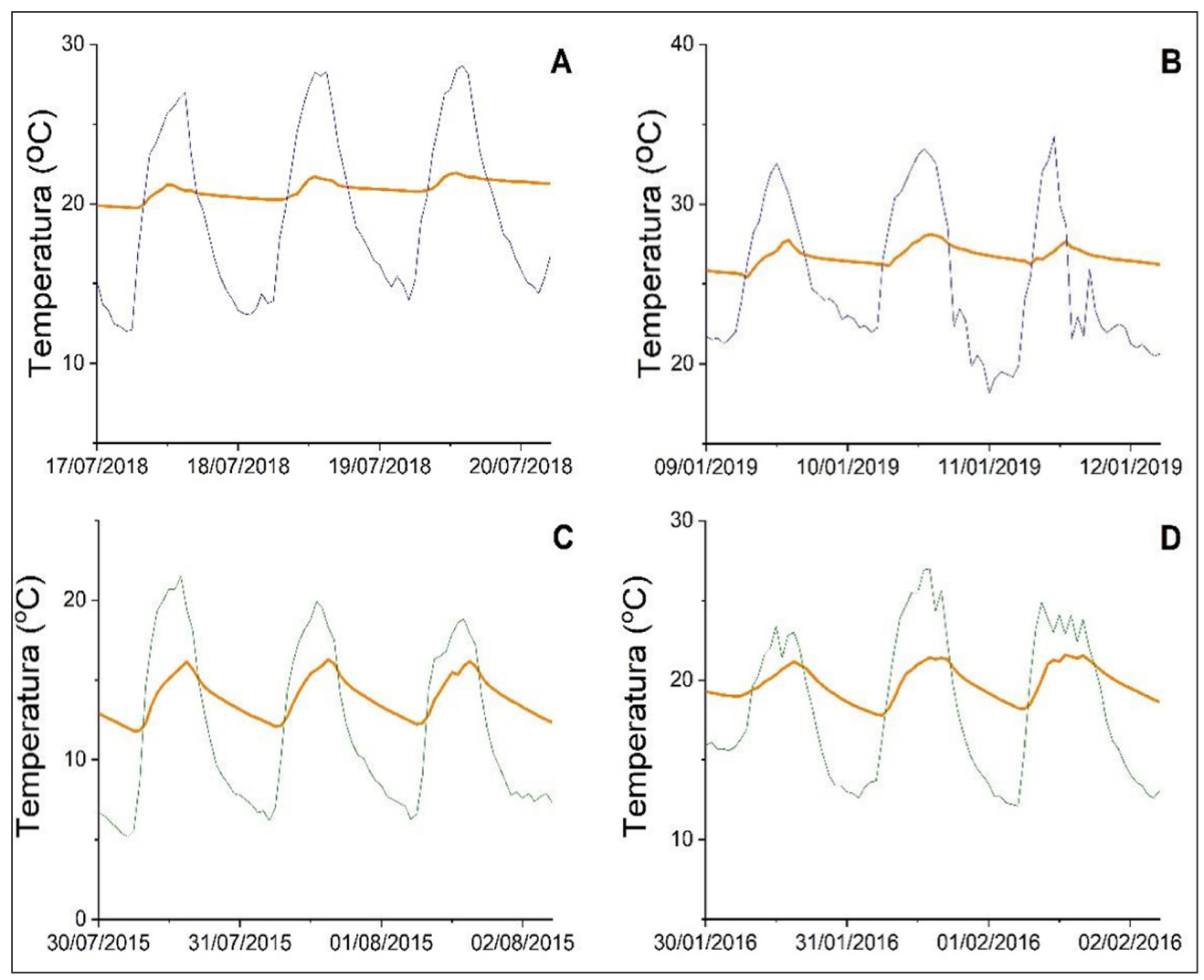

Figura 6 - Sequências de três ciclos diários de temperaturas registrados em dias de estabilidade meteorológica no inverno ( $A$ e $C$ ) e no verão (B e D) na Reserva Técnica do MP ( $A$ e B) e na sala 7 do MX (C e D). Nas Figuras A e B as linhas azuis representam os valores externos e as linhas laranja os valores internos. Nas Figuras C e D as linhas verdes indicam os valores externos e as linhas laranja os valores internos.

Um sinal da importância das atividades de uso da Reserva Técnica nos padrões de flutuação da temperatura pode ser notado por meio dos resultados da Figura 7A, que apresenta os gráficos de caixa (box-and-whisker plots) das amplitudes térmicas desse local em função do dia da semana: claramente as médias de tais valores nos sábados e nos domingos são inferiores àquelas de todos os outros dias da semana, além de os conjuntos de valores serem também mais compactos (ou seja, os desvios padrão são menores). Nos fins de semana o casarão permanece sistematicamente fechado, o ar circula com maior dificuldade (criando uma importante alteração nas trocas de calor do período diurno, porém afetando marginalmente a fase noturna) e os ciclos se tornam menos intensos. 


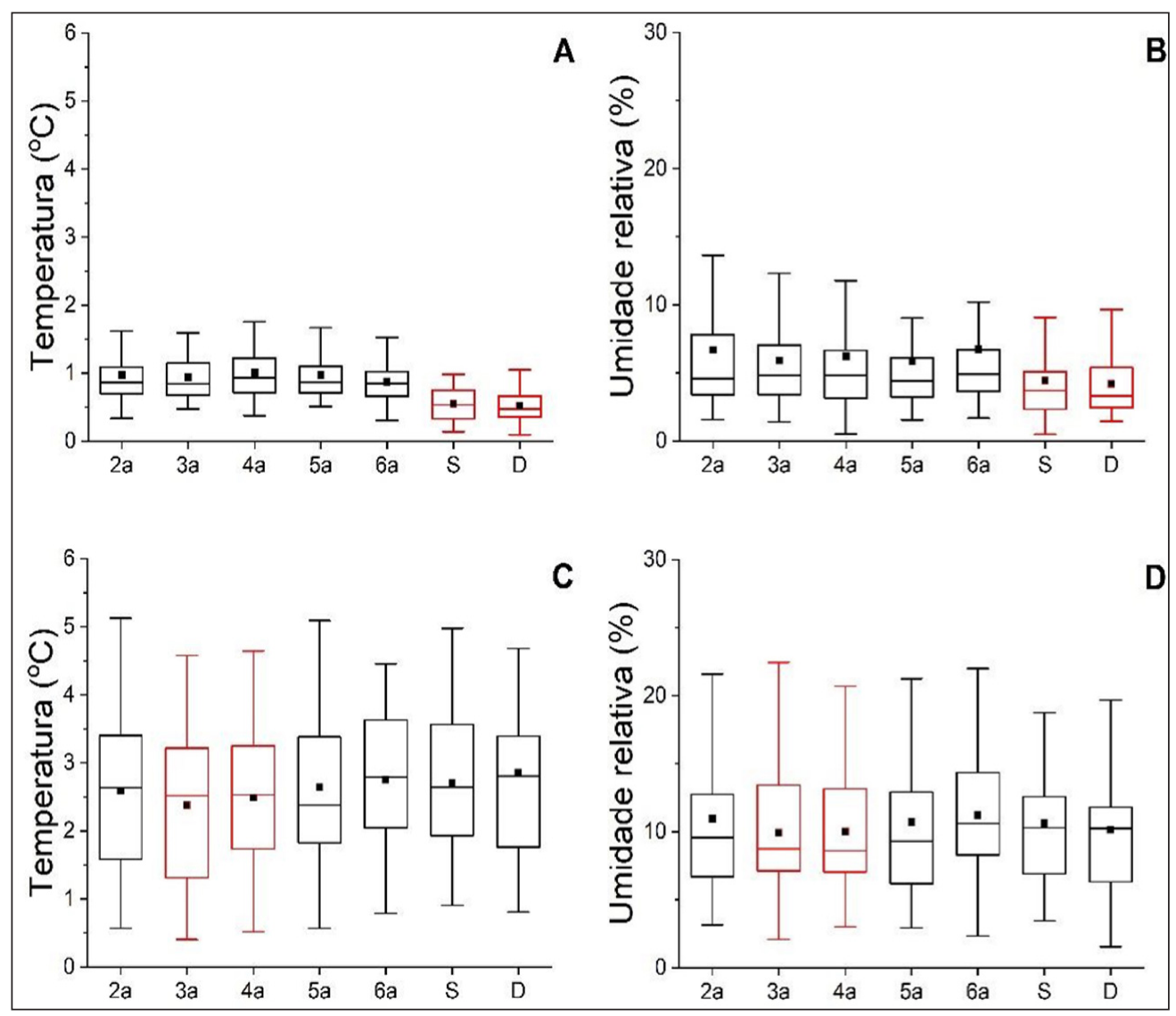

Figura 7 - Gráficos de caixa dos valores das amplitudes de temperatura (A e C) e de umidade relativa (B e D) da Reserva Técnica do MP (A e B) e da sala 7 do MX (C e D), divididos por dia da semana. As amplitudes foram calculadas para todos os dias dos períodos monitorados por meio da diferença entre os valores máximo e mínimo de cada dia. Em vermelho, os dias de suspensão das atividades nos locais.

Nos meses mais quentes (dezembro a abril) as médias internas e externas se aproximam, resultando em $25,0^{\circ} \mathrm{C}$ de média indoor no período e apresentando médias mensais entre 23,8 e $26,6^{\circ} \mathrm{C}$ para a sala da reserva técnica. Portanto, a temperatura média interna aumenta, como esperado, sob influência do clima externo. A diferença entre as máximas externas e internas crescem igualmente, fazendo com que se atenue a influência do clima externo sobre o clima interno nos horários de maior calor (Figura 4A). Como as diferenças entre as mínimas não caem de forma apreciável, vê-se então que as flutuações de temperatura do ambiente interno estão centralizadas em relação àquelas do ambiente externo (Figura 5B) e as médias mensais internas e externas acabam sendo mais próximas do que no inverno. Nesse período, a média das amplitudes diárias é de $0,9^{\circ} \mathrm{C}$. 
A dinâmica diária (Figura 6B) mostra tendências parecidas com as do inverno (portanto, com delay no início do ciclo de aquecimento matutino e amortecimento no processo de resfriamento vespertino/noturno do ambiente interior com relação ao ar exterior), mas apresenta uma discrepância na taxa de aumento da temperatura, que permanece reduzida no ambiente interior, provocando um atraso de uma ou duas horas no horário de máxima temperatura. Possivelmente isso se deve à menor eficiência no processo de aquecimento das paredes da sala da reserva técnica, numa estação em que o Sol está mais inclinado e, consequentemente, atinge as paredes verticais do casarão de forma mais tangencial. Chama a atenção na Figura 5B a inversão mais acentuada na tendência da temperatura nos primeiros horários matutinos (entre oito e nove horas), provavelmente provocada pela rotina de funcionamento do espaço que, ao se iniciar quando o resfriamento ainda está em pleno andamento (inclinação negativa da curva), acarreta uma repentina circulação do ar externo (mais quente). Essa parece ser a única explicação para tal comportamento num horário em que ainda não há incidência solar direta nesse lado do casarão.

Seguindo com a análise dos dados de umidade relativa e lembrando a dependência dessa grandeza em relação à temperatura (relação inversamente proporcional) e a dependência de proporcionalidade direta da umidade absoluta (ou seja, o conteúdo efetivo de vapor de água no ar, em g/ $\mathrm{kg}$ ), destaca-se, como esperado, que o interior da reserva técnica do MP proporciona condições de umidade relativa entre $60-70 \%$ em todo o período (Figura 8A), apresentando tipicamente vinte unidades percentuais abaixo das médias exteriores.

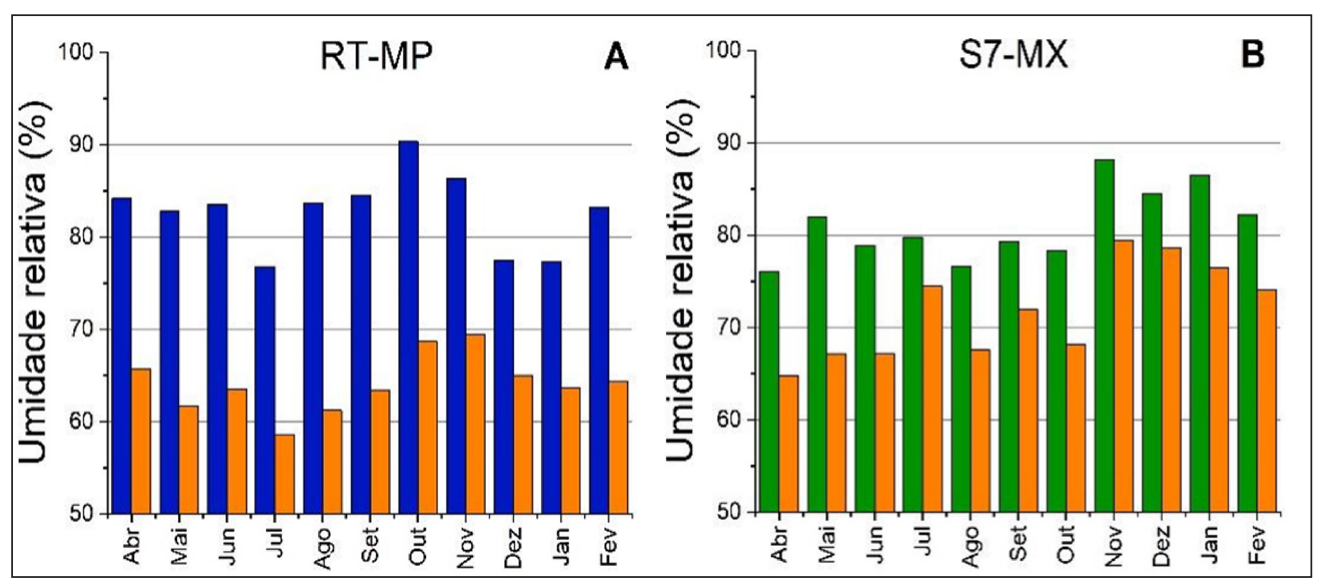

Figura 8 - Médias mensais de umidade relativa na reserva técnica do MP (A) e na sala 7 do MX (B). $\mathrm{Na}$ Figura $\mathrm{A}$ as barras azuis representam os valores externos e as laranjas os valores internos. $\mathrm{Na}$ Figura B as barras em verdes indicam os valores externos e as laranjas os internos. 
A diferença é mais acentuada na faixa dos valores máximos (portanto, noturnos) sobretudo no inverno (Figuras 9A e 10A). Num contexto em que, tipicamente, a quantidade absoluta de vapor de água presente no ar varia, na escala diária, em poucos décimos de $\mathrm{g} / \mathrm{kg}$ (interna e externamente), é evidente que as flutuações de curto prazo da umidade relativa (perfazendo um valor médio de $4,5 \%$ no período de monitoramento, com exclusão do intervalo entre $1^{\circ}$ de janeiro e 15 de fevereiro) decorrem principalmente das variações na temperatura.

Assim, no inverno, as marcantes diferenças de temperatura registradas durante a madrugada (valores mínimos) se refletem nas maiores diferenças em umidade relativa observadas nos mesmos horários (valores máximos). No verão, esse efeito também é observado em relação às umidades relativas mínimas, pois os valores internos tendem a ser mais elevados do que os externos nos horários de temperatura mais elevada (horários de maior secura), ainda que numa proporção menos expressiva (diferenças médias menores que dez unidades percentuais).

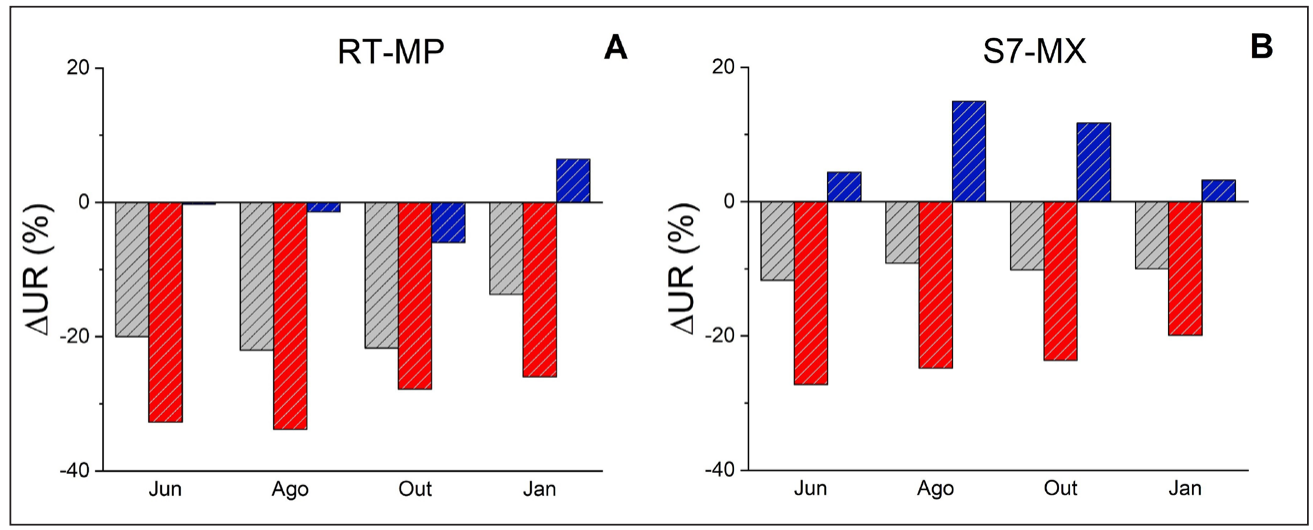

Figura 9 - Diferenças entre as médias mensais internas e externas de umidade relativa na Reserva Técnica do MP (A) e na sala 7 do MX (B). As barras cinzas mostram a diferença entre os valores médios, as azuis entre os valores mínimos e as vermelhas entre os valores máximos.

No período analisado, contudo, foi detectada uma fase (entre os meses de janeiro e fevereiro de 2019) em que, inusitadamente, os valores de umidade relativa mínima alcançados durante vários dias no ambiente interior (Figura 9B) praticamente igualaram ou até ultrapassaram os picos negativos do ambiente externo, com valores de até $15 \%$ no ambiente indoor $\left(1^{\circ}\right.$ de fevereiro de 2019$)$ e marcantes flutuações diárias.

De acordo com os relatos de funcionários e em consulta aos dados meteorológicos locais, nesse período ocorreram dois eventos importantes que 
permitem entender essa situação: um problema de infiltração de água de chuva no interior do casarão em 8 de janeiro de 2019 e uma sequência de dias de escassez de chuva na segunda quinzena do mês $1173 \mathrm{~mm}$ dos $250 \mathrm{~mm}$ de chuva registrados no mês de janeiro de 2019 foram acumulados na primeira quinzena do mês $(70 \%)$, contra $76 \mathrm{~mm}(30 \%)$ registrados na segunda, que teve somente $4 \mathrm{~mm}$ de chuva entre os dias 28 de janeiro e 3 de fevereiro).

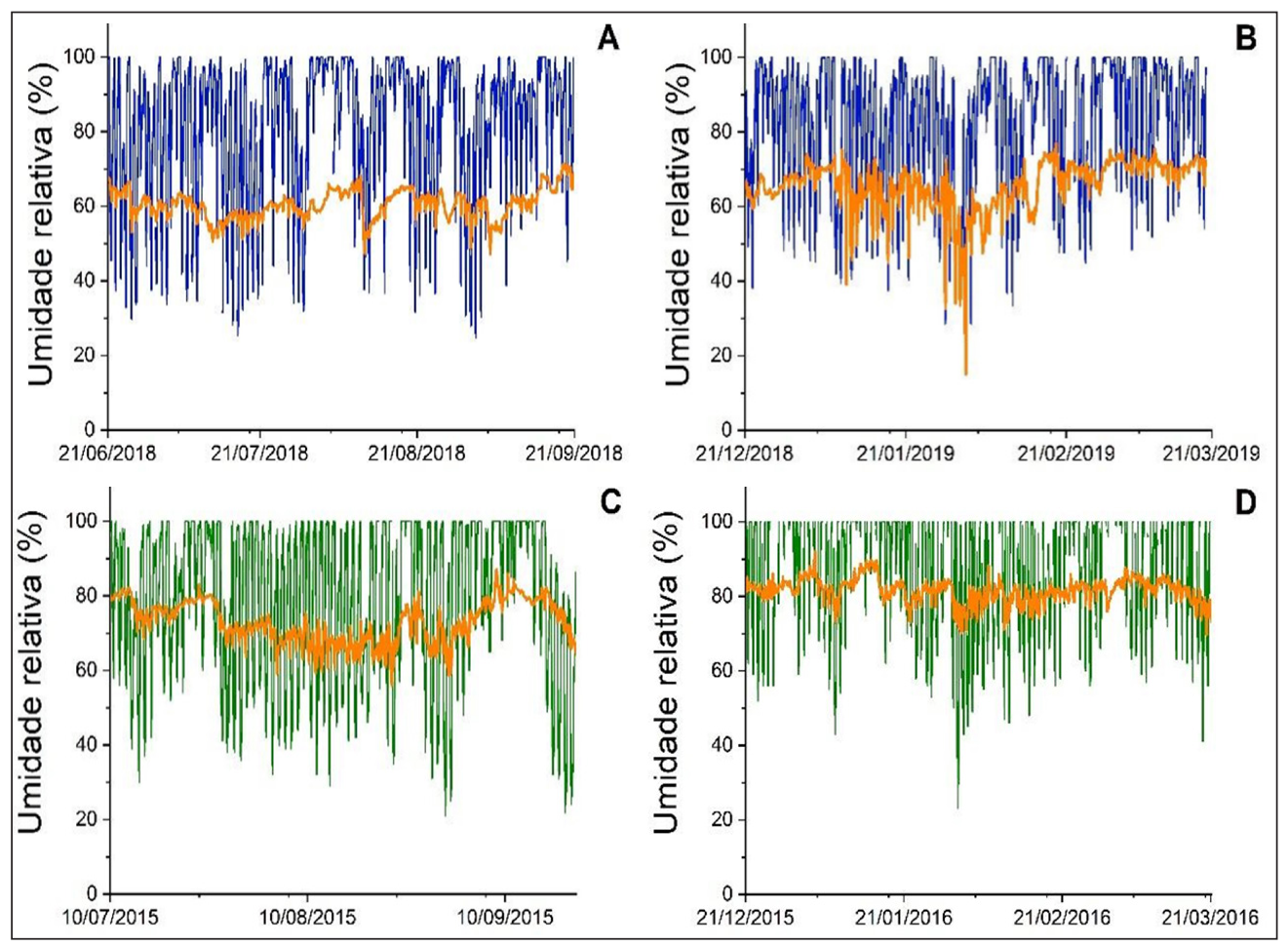

Figura 10 - Gráficos dos valores horários de umidade relativa da Reserva Técnica do MP no inverno (A) e no verão (B), e da sala 7 do $M X$ nas mesmas estações (C e D). Nas Figuras $A$ e B as linhas azuis representam os valores externos e as linhas laranja os valores internos. Nas Figuras $C$ e $D$ as linhas verdes indicam os valores externos e as linhas laranja os valores internos.

A partir dessas informações verificaram-se dois fenômenos capazes de justificar a ocorrência de baixa umidade em $1^{\circ}$ de fevereiro de 2019 : devido à infiltração, nas semanas posteriores ao evento de 8 de janeiro de 2019 houve um incremento na ventilação das salas da Reserva Técnica visando estimular a evaporação do excesso de água; simultaneamente verificou-se uma queda incomum na umidade absoluta do ar nessa região (Figura $11 \mathrm{~A}$ ), alcançando níveis de até $4,3 \mathrm{~g} / \mathrm{kg}$ ainda com temperaturas elevadas $\left(35,6^{\circ} \mathrm{C}\right)$. O resultado foi uma situação de valores de umidade relativa baixíssimos durante o dia, mas relativamente 
elevados à noite em função da presença de estoque de água, temperaturas reduzidas e ambientes fechados após o expediente.

Observa-se, contudo, que em condições de normalidade a sala da Reserva Técnica do MP apresenta valores reduzidos e menos flutuantes de umidade absoluta em relação ao ambiente externo, ainda que siga variações sazonais de menores níveis na estação seca (aproximadamente $10 \mathrm{~g} / \mathrm{kg}$ ) e maiores no verão (aproximadamente $15 \mathrm{~g} / \mathrm{kg}$ ).

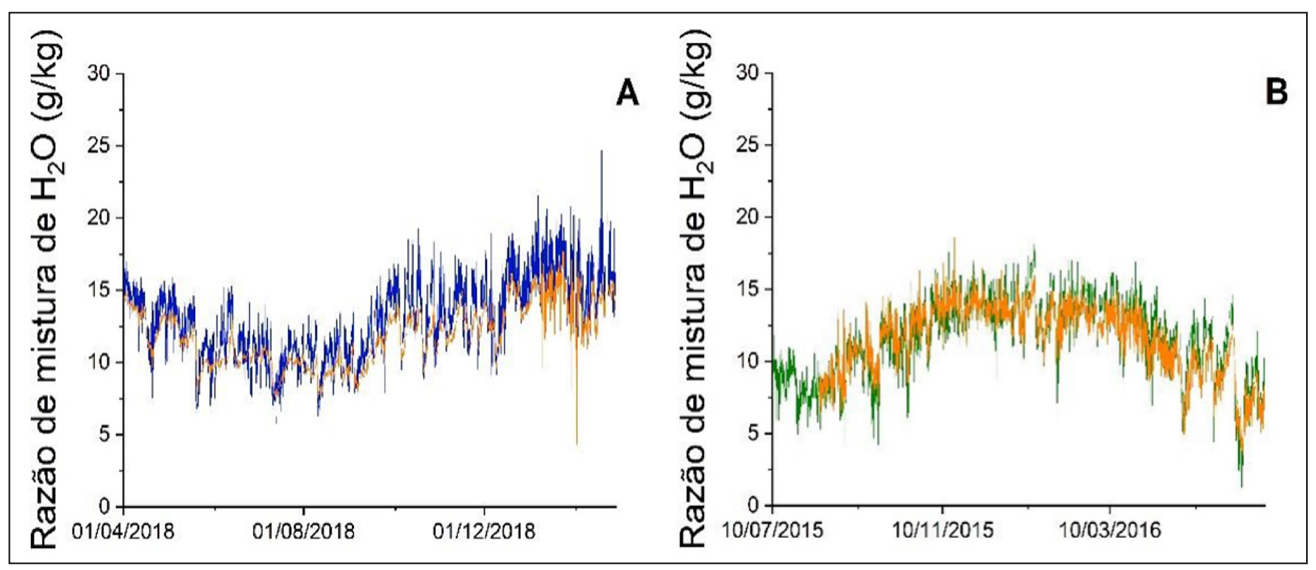

Figura 11 - Valores da razão de mistura do vapor de água (umidade absoluta) na Reserva Técnica do MP (A) e na sala 7 do MX (B). Na Figura A a linha azul representa os valores externos e a linha laranja os valores internos. Na Figura B a linha verde indica os valores externos e a laranja os valores internos.

\section{Resultados da sala de exposição do Museu Casa da Xilogravura}

No caso da sala de exposição (sala 7) do Museu Casa da Xilogravura de Campos do Jordão, observa-se igualmente um perfil de variação sazonal e um quadro em que as médias mensais são mais elevadas no ambiente interno do que no externo (Figura 3B). Devido às diferenças no clima local, influenciadas predominantemente pela diferença de altitude, o regime térmico é nitidamente mais ameno do que no MP. Assim, nos meses mais frios, de abril a setembro, verifica-se uma temperatura média interna de $15,7^{\circ} \mathrm{C}$, sendo abril o mês mais quente (média de $19,3^{\circ} \mathrm{C}$ ) e junho o mais frio (média de $13,0^{\circ} \mathrm{C}$ ). No mesmo período, a média das amplitudes diárias é de $2,9^{\circ} \mathrm{C}$, portanto, o triplo da média observada para o período de maio a novembro no MP.

Uma comparação dos valores das Figuras 7A e 7C confirma essa diferença mesmo na escala anual, ainda que com discrepâncias muito menos expressivas nas médias anuais das amplitudes térmicas do ar externo $19,9{ }^{\circ} \mathrm{C}$ em São Paulo 
contra $10,9{ }^{\circ} \mathrm{C}$ em Campos do Jordão). Tal situação também é claramente percebida na comparação entre as Figuras 5A e 5C.

Trata-se de uma característica específica desse microambiente que decorre da maior exposição da sala a trocas de calor com o ambiente externo. Como se vê por meio do gráfico da Figura 6C, ainda que a taxa de aumento da temperatura na faixa matutina seja parecida com a do MP, esse processo se estende por um intervalo de tempo maior. A curva de resfriamento também é mais íngreme, provocando uma queda maior na temperatura noturna. Esse fato pode ser explicado pela ausência de um segundo pavimento acima da sala monitorada e por seu contato direto com o telhado, ainda que o local esteja no meio da edificação. A influência da abertura dos locais para circulação de funcionários e visitantes é igualmente detectável, seja pelo fato de as amplitudes térmicas diárias serem efetivamente menores nos dias de suspensão das atividades do museu (terça e quarta-feira), como pode ser verificado pelo gráfico da Figura 7C, seja pela clara sobreposição entre as curvas da umidade absoluta interna e externa (Figura 111, pois somente uma rápida e eficiente troca de ar pode justificar tal adesão entre os valores externos, que são determinantes, e os valores internos.

Nos meses mais quentes (entre outubro e fevereiro), a temperatura indoor média mensal se estabiliza em torno dos $20^{\circ} \mathrm{C}$, com flutuações diárias um pouco menos intensas (Figura 5B) e maior proximidade entre as máximas internas e externas (Figura 4B). A maior taxa de aquecimento do telhado com o Sol mais a pino nessa estação deve certamente ter um papel significativo nesse comportamento.

Com relação à umidade relativa, o interior da sala 7 apresenta médias mensais entre $60-70 \%$ nos meses de abril a outubro, e na faixa de $70-80 \%$ de novembro a fevereiro (Figura 8B), com diferenças menos acentuadas quanto ao ambiente externo em relação aos valores mostrados no caso da Reserva Técnica do MP.

As flutuações diárias são particularmente expressivas e, embora sejam em parte decorrentes das amplitudes térmicas, é evidente que apresentam uma contribuição adicional provocada pelas variações de umidade absoluta mencionadas. Isso pode ser apreciado na Figura 12, numa comparação em dois períodos de estabilidade meteorológica na Reserva Técnica do MP e na sala 7 do MX. Observa-se inequivocamente que, enquanto no MP os ciclos de flutuação da umidade relativa são tipicamente diários e marcados por picos negativos correspondentes (conforme mostrado pelas setas) aos picos de aquecimento do ar, no MX as oscilações na umidade relativa têm uma frequência maior. 

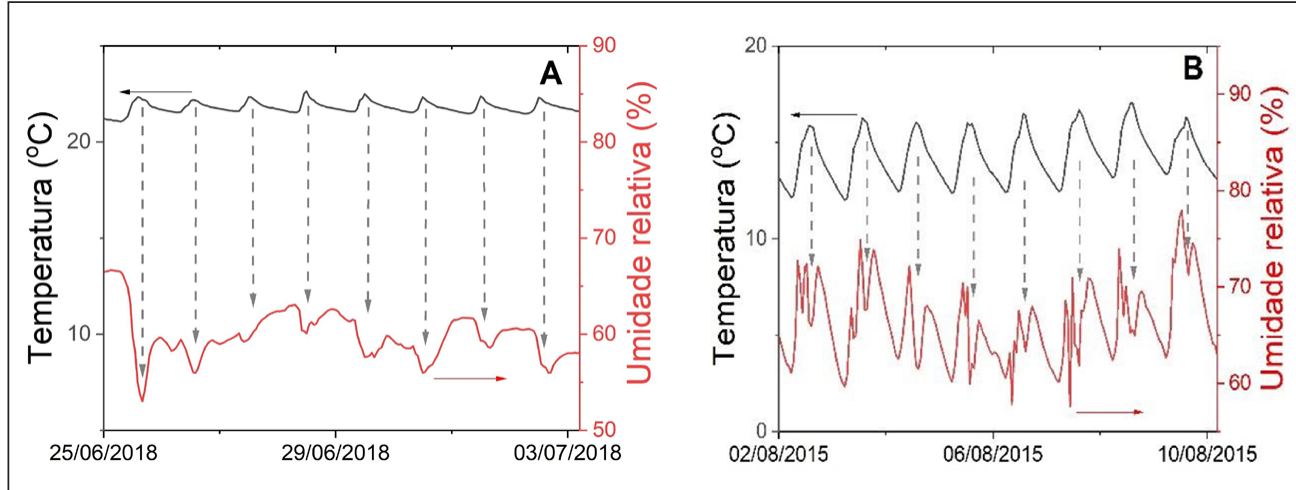

Figura 12 - Sequências de oito ciclos diários de temperatura (linhas pretas) e umidade relativa (linhas vermelhas) registrados em dias de estabilidade meteorológica no inverno na Reserva Técnicas do MP (A) e na sala 7 do $M X(B)$.

Percebe-se que os mesmos efeitos associados aos ciclos térmicos e identificados pelas setas correspondem somente a uma parte das flutuações de umidade relativa e, em geral, àquelas de menor intensidade. Sugere-se que esse padrão, que se repete ao longo do ano, esteja associado a um fenômeno de maior interação entre o ar interno e o externo. Não é possível avaliar em detalhe, nesse contexto e com os dados disponíveis, quanto colaboram para essa situação as peculiaridades arquitetônicas da edificação e a rotina específica adotada pelos gestores no processo de manutenção do prédio e da coleção, bem como a abertura do espaço para a visitação.

\section{Discussões}

O diagnóstico microclimático de espaços de conservação de bens culturais baseado no monitoramento da temperatura e da umidade relativa do ar pode ser objeto de diferentes tipos de aprofundamentos e, sobretudo, provocar respostas variadas por parte das instituições e de suas equipes no intuito de atender à missão de preservação dos acervos. Claramente, toda reação dependerá não somente da habilidade de definir, a partir desses dados, um quadro de riscos para as coleções, mas também da capacidade de traçar um eventual conjunto de estratégias para minimizar ou neutralizar tais riscos, bem como das efetivas condições de implementação de um plano com essa finalidade.

Já foi mencionado que a abordagem tradicional adotada para lidar com a questão de mensurar riscos e direcionar ações práticas se baseia em estabelecer padrões de qualidade microclimática (níveis médios de temperatura e umidade 
relativa e faixas de variabilidade) e colocar em prática programas de gestão voltados para atender tais padrões. Essa linha de trabalho apresenta, incontestavelmente, uma série de vantagens, mas está sendo cada vez mais questionada em várias instâncias, essencialmente com base em dois argumentos principais: (1) o excessivo rigor de tais padrões e a carência de uma fundamentação científica real que justifique a necessidade de parâmetros tão austeros de forma generalizada (portanto, estendidos a diferentes tipos de coleções e a situações climáticas muitos distintas); (2) o fato de que a adoção de metas rígidas pressupõe fatalmente o emprego e a dependência de sistemas mecanizados de controle climático, o que implica, entre outras coisas, em ir de encontro a alguns dos principais preceitos da sustentabilidade e aumentar o viés ecológico das práticas de conservação em museus, arquivos e afins. Esse raciocínio foi bem desenvolvido por Sarah Staniforth em seu texto "Conservation heating to slow conservation: a tale of the appropriate rather than the ideal" no qual se defende, como possivel saída, a ideia de que o conservador possa aderir a uma conduta inspirada na lógica da slow conservation, num paralelismo com o movimento slow food. ${ }^{45}$

Um aspecto complementar a esse raciocínio é que o conservador, consciente dos efeitos de natureza física, química e biológica dos níveis de temperatura e umidade relativa do ar num determinado espaço - e da extensão das respectivas flutuações - deveria se preocupar antes com a obtenção de condições adequadas do que em atingir uma situação ideal. ${ }^{46}$ Tal proposição direcionaria a ação do conservador para buscar um aprimoramento gradativo das condições ambientais de seus espaços de conservação, sempre de forma que tais desenvolvimentos sejam efetivamente sustentáveis pela instituição e, portanto, em concordância com suas efetivas capacidades de manutenção de forma estável em termos de gestão. Nesse sentido, não somente deveria lançar um olhar para o clima local e dispensar ou minimizar o uso de sistemas de controle mecanizado do microclima, mas também buscar otimizar oportunidades passivas e a participação colaborativa da comunidade de profissionais atuantes nas diferentes esferas da instituição.

Assim, considerando os resultados do diagnóstico realizado na Reserva Técnica do MP à luz dessas premissas, destacam-se os seguintes pontos:

Primeiro, evidencia-se um quadro positivo em relação à estabilidade de curto prazo da temperatura e umidade relativa, isso é, com flutuações diárias menores que $1^{\circ} \mathrm{C}$ na temperatura e menores que $5 \%$ na umidade relativa, o que está, inclusive, muito próximo dos índices mais tradicionais. Como antecipado, acredita-se que essa situação decorra de uma combinação de fatores que incluem a posição da sala em relação à incidência de radiação solar, o bom desempenho do sistema arquitetônico na amenização das variações noturnas e a ausência de fenômenos (fontes internas, 
47. <http://dpcalc.org/>. Acesso em: 15 fev. 2021. Conforme bem sumarizado por Gonçalves (2013), a definição do PI feita por essa instituição decorre essencialmente da ideia de que a velocidade de degradação química é proporcional à concentração de vapor de água e segue a lei de Arrehenius da dependência exponencial com a temperatura. transporte do ambiente exterior) que aumentem a umidade absoluta do ar no interior da Reserva Técnica. Ter plena consciência da existência desse tipo de situação benéfica, que limita a ocorrência de processos mecânicos de desgaste numa coleção em que os artefatos fotográficos ficam potencialmente muito expostos a esse tipo de mecanismo de degradação, é a primeira etapa de qualquer processo de decisão envolvendo direta ou indiretamente a conservação do acervo, inclusive quando da definição de eventuais mudanças ou transferências. Ficou claro, contudo, que se trata de uma condição vulnerável, como mostrou o acidente ocorrido em janeiro de 2019, quer em relação a quanto a estrutura da edificação está sujeita a episódios meteorológicos extremos, ou quanto à ausência de mecanismos de detecção de anomalias microclimáticas e de correta contenção de danos lo vazamento efetivamente disparou ações de resposta, mas nem todos os aspectos e consequências de tais ações foram levados em consideração ou monitorados).

Segundo, no que diz respeito aos valores da temperatura e umidade relativa, à luz do bom grau de estabilidade diária do espaço, faz sentido trabalhar com valores médios mensais e se deter em diferenças sazonais. Além disso, cabe lembrar que esses parâmetros estão sobretudo ligados ao envelhecimento/ degradação químico/a e à biodeterioração, e que, na perspectiva praticamente unânime dos cientistas da conservação, em termos puramente teóricos, quanto menores forem a temperatura e a umidade, menores serão as taxas de ocorrência de tais processos. Valores muito baixos são impraticáveis e/ou provocam outros efeitos: por exemplo, temperaturas muito baixas induzem ao aumento da umidade relativa ou, eventualmente, congelamento; e umidade muito baixa provoca a desidratação de materiais higroscópicos. Nessa perspectiva, os dados do diagnóstico microclimático podem ser usados para apontar situações de disparidade sazonal nas condições ambientais e indicar possíveis ações mitigatórias. No caso da Reserva Técnica do MP, observou-se que, enquanto na estação mais fria é possível manter determinado patamar de temperaturas controladas sem quaisquer intervenções mecanizadas (resfriamento/calefação ou (des)umidificação) e sem aumentar a umidade relativa, nos meses mais quentes houve um claro incremento de ambos os fatores. A mero título de comparação quantitativa, e usando como parâmetro de referência numérica o fator PI proposto pelo Image Permanence Institute, ${ }^{47}$ entre os meses de maio e novembro (PI médio de 27, com temperatura média de $21,3{ }^{\circ} \mathrm{C}$ e umidade relativa média de $64 \%$ ) e de dezembro a abril (PI médio de 16 , temperatura média de $25,0^{\circ} \mathrm{C}$ e umidade relativa média de $65 \%$ ) houve um aumento relativo de $39 \%$ na capacidade do ambiente de acelerar processos de decaimento químico. Ocorreu que tanto a temperatura como a umidade absoluta do ar aumentaram, mas os dois efeitos se compensaram, 
deixando a umidade relativa num patamar médio estável. Uma possível abordagem seria buscar uma equiparação entre a qualidade ambiental (Pls mais próximos) das duas estações por meio de recursos de controle passivo. A amenização da temperatura poderia ser obtida com a menor incidência de radiação solar nos horários de maior (uso de cortinas, persianas ou breezes nas janelas; vegetação mais fechada ao redor da casa ${ }^{48}$ e menor circulação do ar, com planejamento das atividades na Reserva Técnica. Nos horários noturnos, o incremento controlado da ventilação é uma alternativa possível: em 62\% das medições válidas registradas no período em questão a temperatura externa foi menor do que a interna e, entre elas, $17 \%$ das vezes a umidade absoluta interior era menor do que a exterior. Isso significa que em 10\% dos horários monitorados durante os meses mais quentes seria possível misturar ao ar interno o ar externo, mais fresco e menos úmido, de forma a proporcionar alguma redução na temperatura sem introduzir quantidades muito expressivas de vapor de água adicional, minimizando, portanto, efeitos sobre a umidade relativa. Trata-se de uma estimativa grosseira que requereria avaliações e cálculos mais precisos ou, no mínimo, uma implementação acompanhada por um monitoramento cuidadoso. Ainda assim, mostra a existência de elementos que podem ser explorados numa abordagem desvinculada do uso de sistemas de controle mecanizado. ${ }^{49}$ Outras soluções passivas complementares ajudariam a manejar a umidade relativa e suas flutuações (uso de materiais capazes de tamponar a presença de vapor de água no ar) e a controlar pragas e substâncias poluidoras do ar (sistemas de ventilação dotados de filtros oportunos). ${ }^{50}$

No caso da situação evidenciada da sala de exposição do MX, o quadro microclimático apresenta características bastante distintas que levam às seguintes considerações: os valores médios de temperatura no interior do museu, ligados às características microclimáticas da região, representam o fator mais favorável do diagnóstico. No entanto, cabe destacar que são também responsáveis pela manutenção dos níveis de umidade relativa em patamares considerados propícios a processos de biodeterioração. Dessa forma, buscar melhor controle desse fator ambiental pode ser considerado um alvo prioritário num eventual processo de aprimoramento das condições de conservação. Contudo, amenizar a umidade relativa não parece ser uma tarefa fácil, pois observa-se que suas maiores médias são registradas no verão, sugerindo que a temperatura não aumenta, em média, o suficiente nessa estação a ponto de garantir teores médios sistematicamente mais próximos aos valores dos meses mais frios. Por outro lado, notaram-se sinais claros da influência da circulação do ar na introdução de vapor de água do ambiente externo. Assim, pode-se dizer que, nessa estação, ocorre um aumento generalizado da umidade absoluta - favorecido pelas trocas entre o ambiente indoor e outdoor
48. Outros recursos dessa natureza são apresentados no âmbito da bioarquitetura, conforme revisão de Gonçalves (2013).

49. O uso de ventilação natural ou forçada como estratégia de controle ambiental, complementada por simulações fluidodinâmicas, foi objeto de um estudo primoroso de Gonçalves (2013).

50. A discussão está desconsiderando um outro importante fator de degradação que, claramente, precisa ser levado em consideração em casos que envolvem processos de mistura de ar interno e externo, a dizer, a presença de poluentes químicos gasosos. 
- não contrabalanceado por um aumento médio da temperatura. De acordo com uma perspectiva de gestão inspirada nos cânones da sustentabilidade e, portanto, dispensando a ideia de sistemas mecânicos de remoção de umidade (provavelmente de escassa eficiência num espaço com ambientes altamente interconectados), as soluções deveriam privilegiar a redução da taxa de ventilação ou a adesão a sistemas inteligentes de circulação do ar em função das relações indoor/outdoor desse parâmetro. Essa estratégia teria a potencialidade de contribuir para reduzir as flutuações de umidade relativa ligadas também à introdução de vapor de água dentro do casarão. Alternativamente, enxerga-se a possibilidade de tolerar níveis mais elevados de umidade relativa (notando que, com a temperatura média de $20{ }^{\circ} \mathrm{C}$ e a umidade relativa média de 70\%, o Pl do ambiente ainda seria comparável com aquele dos meses frios na Reserva Técnica do MPI, mas com um monitoramento rigoroso da contaminação microbiológica e da infestação de pragas.

\section{CONSIDERAÇÕES FINAIS}

Na perspectiva da adesão da atividade do conservador aos princípios da sustentabilidade, a realização de um diagnóstico das características ambientais dos espaços disponíveis e de suas dinâmicas temporais constitui o ponto de partida para definir estratégias de preservação de coleções culturais que valorizem as potencialidades inerentes às propriedades arquitetônicas e aos modelos de gestão, e que sejam voltadas para mitigar vulnerabilidades.

trabalho apresentado neste artigo, ainda que parcial, pois deixou de considerar aspectos importantes como a presença de agentes químicos e biológicos, ou ainda a incidência de radiação luminosa, apresenta possíveis caminhos para entender as características microclimáticas de uma forma que permita conceber ou reavaliar políticas internas de uso e gerenciamento de espaços, conciliando a missão da instituição e as necessidades (se não a oportunidade, como se tentou mostrar) do emprego de soluções passivas de controle ambiental.

Os dados destacaram importantes diferenças de comportamento das salas investigadas, decorrentes em parte das diversidades climáticas de cada localidade e, em parte, das distintas características das edificações e de suas formas de uso - fato que ressalta a importância de se desconfiar de avaliações puramente intuitivas e se investir em estudos individualizados. No caso em questão, não há pretensão de desvendar todas as relações de causa e efeito referentes aos aspectos evidenciados, nem mesmo de que todos os aspectos relevantes tenham sido 
apurados. Por esse motivo, certamente demandam-se aprofundamentos e pesquisas ulteriores, ou mesmo o emprego de ferramentas adicionais.

Cabe alertar que a identificação das soluções para algumas questões relevantes apontadas pelo diagnóstico não constituiu o objetivo principal deste trabalho e os exemplos apresentados atenderam ao intento de mostrar a viabilidade de caminhos alternativos, muitas vezes de simples implementação, concretizando de fato a conexão entre sustentabilidade e conservação.

\section{AGRADECIMENTOS}

Os autores agradecem à disponibilidade e colaboração do Prof. Dr. Antonio Fernando Costella e da Sra. Leda Campestrin Costella do Museu Casa da Xilogravura, assim como da Profa. Dra. Solange Ferraz de Lima e toda a equipe do Serviço de Documentação Histórica e Iconografia do Museu Paulista. 


\section{REFERÊNCIAS}

LIVROS, ARTIGOS E TESES

ASHLEY-SMITH, Jonathan; UMNEY, Nick; FORD, David. Let's be honest: realistic environmental parameters for loaned objects. Studies in Conservation, Abingdon, v. 39, p. 28-31, 1994.

AVRAMI, Erica. Sustainability and the built environment: forging a role for heritage conservation. Conservation Perspectives: The CGI Newsletter, Los Angeles, v. 26, n. 1, p. 4-10, 2011. Disponível em: <http://bit.ly/2Zjdc8d>. Acesso em: 12 jul. 2020.

BOERSMA, Foekje; DARDES, Kathleen; DRUZIK, James. Precaution, proof, and pragmatism evolving perspectives on the museum environment. Conservation Perspectives: The GCI Newsletter, Los Angeles, v. 29, n. 2, p. 4-9, 2014. Disponível em: <http://bit.ly/2Nrz7r9>. Acesso em: 15 maio 2020.

CASSAR, May. Sustainable heritage: challenges and strategies for the Twenty-First Century. APT Bulletin: The Journal of Preservation Technology, Springfield, v. 40, n. 1, p. 3-11, 2009. Disponível em: <https://bit.ly/2RnWrVs>. Acesso em: 1 jun. 2019.

CAVICCHIOLI, Andrea. Perspectivas cooperativas entre academia e conservadores na caracterização ambiental para a conservação preventiva de bens culturais. Revista CPC, São Paulo, n. 23, p. 245-273, 2017.

CAVICCHIOLI, Andrea; ALEGRE, Priscila Leitão Denardi; MARTINS, Ariel Guilger Simões. Microambientes e conservação preventiva em áreas indoor: o caso do espaço interior não climatizado da Casa de Dona Yayá, em São Paulo (Brasil). Anais do Museu Paulista, São Paulo, v. 25, n. 3, p. 291-340, 2017.

DE SILVA, Megan; HENDERSON, Jane. Sustainability in conservation practice. Journal of the Institute of Conservation, Abingdon, v. 34, n. 1, p. 5-15, 2011.

FERRONI, Eduardo et al. A preparação do Museu do Ipiranga para o Bicentenário da Independência em 2022. Revista Restauro, São Paulo, v. 4, n. 7, 2020. Disponível em: https:// bit.ly/3u0z6eu. Acesso em: 8 ago. 2020. 
FRONER, Yacy-Ara. International policies for sustainable development from cultural empowerment. Journal of Cultural Heritage Management and Sustainable Development, Bingley, v. 7, n. 2, p. 208-223, 2017.

GONÇALVES, Willi de Barros. Métricas de preservação e simulações computacionais como ferramentas diagnósticas para a conservação preventiva de coleções: estudo de caso no Sítio Patrimônio Mundial de Congonhas. 2013. Tese (Doutorado em Artes) - Escola de Belas Artes, Universidade Federal de Minas Gerais, Belo Horizonte, 2013.

GONÇALVES, Willi de Barros; SOUZA, Luiz Antônio Cruz. O debate contemporâneo sobre as interfaces transdisciplinares de dois campos de conhecimento em consolidação: a ciência da sustentabilidade e a ciência do patrimônio. Pós, Belo Horizonte, v. 4, n. 7, p. 84-102, 2014.

GONÇALVES, Willi de Barros; SOUZA, Luiz Antônio Cruz; FRONER, Yacy-Ara. Edifícios que abrigam coleções. Belo Horizonte: Lacicor, 2008.

KING, Steve; PEARSON, Colin. Controle ambiental para instituições culturais: planejamento adequado e uso de tecnologias alternativas. In: MENDES, Marylka et al. (orgs.). Conservação: conceitos e práticas. Rio de Janeiro: UFRJ, 2001. p. 41-64.

MACLEOD, Ian D. Micrometeorological assessment of passive climate controls for museums. AICCM Bulletin, Abingdon, v. 36, p. 33-43, 2015.

MAEKAWA, Shin et al. Climate controls in a historic house museum in the tropics: a case study of collection care and human comfort. In: CONFERENCE ON PASSIVE AND LOW ENERGY ARCHITECTURE, 26., 2009, Quebec. Anais [...]. Hong Kong: Plea, 2009. p. 1-6. Disponível em: <https://bit.ly/3kguTh3>. Acesso em: 10 maio 2020.

MAEKAWA, Shin; TOLEDO, Franciza. Sustainable climate control for historic buildings in hot and humid regions. In: CONFERENCE ON PASSIVE AND LOW ENERGY ARCHITECTURE, 18., 2001, Florianópolis. Anais [...]. Hong Kong: Plea, 2001. p. 1-7. Disponível em: <https://bit. ly/3hv4wlO>. Acesso em: 10 maio 2020.

MAKINO, Miyoko et al. O Serviço de Documentação Textual e Iconografia do Museu Paulista. Anais do Museu Paulista, São Paulo, v. 10, n. 11, p. 259-304, 2003.

MENDES, Manuel Cardoso. Museus como pioneiros para a sustentabilidade ambiental. Museologia e Interdisciplinaridade, Brasília, DF, v. 1, n. 2, p. 72-84, 2012. 
NEVES, Letícia de Oliveira. Arquitetura bioclimática e a obra de Severiano Porto: estratégias de ventilação natural. 2006. Dissertação (Mestrado em Arquitetura e Urbanismo) - Escola de Engenharia de São Carlos, Universidade de São Paulo, São Carlos, 2006.

NIMER, Edmon. Climatologia do Brasil. 2. ed. Rio de Janeiro: IBGE, 1989.

PADFIELD, Tim; LARSEN, Poul Klenz. How to museums with a naturally stable climate: the evolution of museum buildings. Studies in Conservation, London, v. 49, n. 2, p. 1-14, 2003.

PAULA, Teresa Cristina Toledo de. De Plenderleith a Al Gore: o ideário vigente na conservação de bens culturais móveis no século XXI. Anais do Museu Paulista: História e Cultura Material, v. 16, n. 2, p. 241-264, 2008. DOI: 10.1590/S0101-47142008000200008. Disponível em: <https:// bit.ly/3dJS2Ze>. Acesso em: 24 fev. 2021.

RIBEIRO, Marina Byrro; LOMARDO, Louise Land Bittencourt. Bioclimatic museum architecture in historic buildings: instrument of environmental sustainability. In: AMOÊDA, Rogério; LIRA, Sérgio; PINHEIRO, Cristina (eds.). Heritage 2016: Proceedings of the 5th International Conference on Heritage and Sustainable Development. Barcelos: Green Lines Institute, 2016. p. 593-606. Disponível em: <https://bit.ly/35zFnUH>. Acesso em: 8 mar. 2020.

RYHL-SVENDSEN, Morten et al. A museum storage facility controlled by solar energy. In: ASHLEY-SMITH, Jonathan; BURMESTER, Andreas; EIBL, Melanie (eds.). Climate for collections: standards and uncertainties. London: Archetype, 2013. p. 1-11. Disponível em: <https://bit. 1y/35zZq5o>. Acesso em: 13 jul. 2020.

SAUNDERS, David. Climate change and museum collections. Studies in Conservation, London, v. 53, n. 4, p. 287-297, 2008.

SILVA, Liliana Sousa e. Sustentabilidade na cultura: da diversidade cultural à sustentação financeira. In: SEMINÁRIO INTERNACIONAL POLÍTICAS CULTURAIS, 2., 2011, Rio de Janeiro. Anais [...]. Rio de Janeiro: Fundação Casa de Rui Barbosa, 2011. p. 1-13. Disponível em: <https://bit.ly/33so0CK>. Acesso em: 29 jul. 2018.

STANIFORTH, Sarah. Conservation heating to Slow Conservation: A tale of the appropriate rather than the ideal. In: CONTRIBUTIONS TO EXPERTS ROUNDTABLE ON SUSTAINABLE CLIMATE MANAGEMENT STRATEGIES, 2007, Tenerife. Los Angeles: The Getty Conservation Institute, 2008, p. 1-17. Disponível em: <https://bit.ly/2ZHqGuV>. Acesso em: 18 fev. 2021. 
STANIFORTH, Sarah. Slow conservation. Studies in Conservation, London, v. 55, n. 2, p. 74$80,2010$.

TEIJGELER, René. Conservação preventiva da herança documental em climas tropicais: uma bibliografia anotada. Lisboa: Biblioteca Nacional de Portugal, 2007. Disponível em: <https:// bit.ly/3hxsY6f>. Acesso em: 8 set. 2020.

TERRA, Carina; SAFT, Juliana Bechara. Avaliação de desempenho técnico-construtivo: estudo de caso da "Casa Branca" do Museu Paulista. 2017. Relatório (Pós-graduação em Arquitetura e Urbanismo) - Faculdade de Arquitetura e Urbanismo, Universidade de São Paulo, São Paulo, 2017.

TOLEDO, Franciza Lima. Controle ambiental e preservação de acervos documentais nos trópicos úmidos. Acervo, Rio de Janeiro, v. 23, n. 2, p. 71-76, 2010.

TOLEDO, Franciza Lima. The role of architecture in preventive conservation. Roma: ICCROM, 2006. Disponível em: <https://bit.ly/2FtEdj4>. Acesso em: 8 mar. 2020.

Artigo apresentado em: 15/09/2020. Aprovado em: 22/12/2020.

\section{(cc) BY}

